\title{
El alma de Mesoamérica: unidad y diversidad en las concepciones anímicas
}

Roberto Martínez González

\section{(2) OpenEdition}

1 Journals

Edición electrónica

URL: https://journals.openedition.org/jsa/7673

DOI: $10.4000 /$ jsa. 7673

ISSN: 1957-7842

Editor

Société des américanistes

\section{Edición impresa}

Fecha de publicación: 2 diciembre 2007

Paginación: 7-49

ISSN: 0037-9174

\section{Referencia electrónica}

Roberto Martínez González, «El alma de Mesoamérica: unidad y diversidad en las concepciones anímicas», Journal de la Société des américanistes [En línea], 93-2 | 2007, Publicado el 10 diciembre 2012, consultado el 02 septiembre 2022. URL: http://journals.openedition.org/jsa/7673 ; DOI: https:// doi.org/10.4000/jsa.7673 


\title{
EL ALMA DE MESOAMÉRICA: UNIDAD Y DIVERSIDAD EN LAS CONCEPCIONES ANÍMICAS
}

\author{
Roberto MARTÍNEZ GONZÁLEZ *
}

\begin{abstract}
A fin de ilustrar la unidad y diversidad de la cosmovisión mesoamericana, compararemos diversas concepciones anímicas indigenas. A partir de este procedimiento, reconoceremos aquello que tiende a mantenerse constante a través del espacio y la cultura. Identificaremos cuatro tipos principales de almas: corazón, aliento, sombra y calor. Una vez descritos estos elementos, explicaremos, hipotéticamente, el modo en que se articulaban bajo el esquema mítico del Quinto Sol. [Palabras claves: almas, energía vital, Mesoamérica, núcleo central, límites culturales.]
\end{abstract}

L'âme en Mésoamérique: unité et diversité des conceptions animique. Afin d'illustrer l'unité et la diversité de la cosmovision mésoaméricaine, on comparera diverses conceptions indigènes de l'âme et, à partir de ce travail, on repérera ce qui tend à rester constant dans l'espace et la culture. On identifiera quatre types principaux d'âmes mésoaméricaines: le cœur, le souffle, l'ombre et la chaleur. Une fois décrits ces éléments, on avancera des hypothèses sur la manière dont ceux-ci s'articulent dans le schéma mythique du Cinquième Soleil. [Mots-clés: âmes, énergie vitale, Mésoamérique, noyau central, délimitation culturelle.]

The Mesoamerica's soul: unity and diversity of soul conceptions. In order to illustrate the unity and diversity of the Mesoamerican world-view, we will compare different native conceptions of the soul. From this procedure we will recognize those elements that tend to keep constant across space and culture, identifying four types of soul: heart, breath, shadow and heat. Once described, we will explain, hypothetically, the manner in which these elements articulate under in the mythic scheme of the Fifth Sun. [Key words: souls, vital energy, Mesoamerica, central nucleus, cultural delimitation.]

Aunque ya desde el siglo xvi los frailes habían comenzado a notar las enormes semejanzas entre las tradiciones culturales de los pueblos indígenas de esta zona,

* Instituto de investigaciones antropológicas, UNAM, avenida del Imán 660, ed 30-501, CP 04720, Pedregal del Maurel, Coyoacan, México, DF, Mexique [nahualogia@yahoo.com.mx].

Journal de la Société des Américanistes, 2007, 93-2, pp. 7-49. (O Société des Américanistes. 
no fue sino hasta hace sesenta y cuatro años que, gracias a la aguda intuición de Paul Kirchhoff (1943), fue acuñada una de las nociones que han tenido mayor impacto en la antropología americana: el concepto de Mesoamérica. Cabe aclarar, sin embargo, que en aquel tiempo no se hablaba de una unidad ideológicocultural sino tan sólo de compartir una serie de rasgos culturales tan diversos como el sacrificio humano, el juego de pelota y el cultivo de maíz y frijol. En épocas más recientes, algunos investigadores, como Alfredo López Austin (2001), han procurado redefinir esta área cultural a partir de la existencia de cierta unidad en los sistemas de pensamiento; en la que, más que una uniformidad total, existiría una matriz de ideas compartidas, o núcleo duro, y una serie de elementos que tienden a modificarse a través del tiempo, el espacio y los individuos.

Así pues, en el presente trabajo hemos querido tratar la unidad y diversidad del pensamiento mesoamericano a partir del estudio de una de sus más íntimas creencias, la idea del alma ${ }^{1}$. De antemano podemos advertir que, aunque fuimos incapaces de identificar un núcleo duro de las concepciones anímicas, la presente investigación muestra con claridad las diversas problemáticas por las que atraviesa el estudio del alma en nuestra región de interés.

Siendo que lo que aquí nos interesa es justamente abordar el tema de la unidad cultural de Mesoamérica, hemos decidido comparar las creencias de los pueblos que nos atañen con las de grupos de regiones vecinas. A partir de esta analogía, mostraremos que algunas de las ideas que solemos considerar netamente mesoamericanas se encuentran igualmente presentes en otras poblaciones del continente. Y que, si queremos comprender mejor le conformación de esta área cultural, también debemos tomar en cuenta los intercambios simbólicos que pudieron tener lugar con sociedades extramesoamericanas. De este modo, concluiremos, al final de este trabajo, que aquello que se comparte en Mesoamérica no son las almas en sí, sino un cierto esquema anímico que eventualmente puede verse alterado por influencias exógenas. Las comparaciones con culturas vecinas tienen como objetivo relativizar el concepto de Mesoamérica y ayudar a comprender mejor la unidad, especificidad y diversidad de los conceptos aquí tratados. La idea central es que, aun si la idea de Mesoamérica es fundamental para la antropología americana, hay creencias indígenas que la sobrepasan y que parecen ser mucho más generales de lo que uno tendería a suponer ${ }^{2}$.

Dado que, en una sola vida, sería imposible abarcar las creencias anímicas de todos los pueblos indígenas americanos, hemos decidido tomar a una simple muestra como punto de comparación. Para ellos hemos considerado tanto a grupos de las inmediaciones de Mesoamérica - y que posiblemente habrían estado influenciados por ella - como a otros de zonas mucho más alejadas - y que, a priori, deberían haber tenido con ésta un contacto más limitado ${ }^{3}$. Salvo estas consideraciones, nuestro principal criterio ha sido el de la disponibilidad de la información. 


\section{EN bUSCA DEL ALMA MESOAMERICANA}

Lo primero que podemos notar, al tratar el tema de las entidades anímicas mesoamericanas, es que la cantidad y la calidad de la información disponible no son, en modo alguno, homogéneas. Existen grupos, como los nahuas y los mayas de los Altos de Chiapas, sobre los que se ha alcanzado tal detalle en su conocimiento que, en ocasiones, podemos identificar variaciones regionales, locales e incluso personales. En cambio, encontramos etnias sobre las que la información es tan escasa, tan inaccesible o tan poco específica que prácticamente no nos dice nada sobre las concepciones indígenas. Este es, por ejemplo, el caso de los triques, los tepehuanes, los chuj, los lencas, los tolupan-jicaques, los popolocas, los mazahuas y los mazatecos. Ello, sin tomar en consideración la existencia de poblaciones indígenas, ahora casi extintas, sobre las que la información es nula o completamente inaccesible; tal es el caso de los paipai, los cochimíes, los kiliwa, los diegueño, y los pimas, por citar algunos.

A partir de la información que sí está a nuestro alcance, hemos podido observar que, contrariamente a lo que comúnmente se plantea las concepciones anímicas mesoamericanas suelen ser sumamente variables en el tiempo y el espacio.

El número de entidades consideradas oscila entre cuatro y una, siendo uno y dos los números más frecuentes, y pudiéndose encontrar en un mismo grupo étnico, e incluso una misma región, una cantidad distinta de almas. En la colonia temprana, Urbano (1990) registró cuatro términos otomíes referentes al « alma » o " ánima », más tarde López Yepes (1826) uno, y los antropólogos modernos dos. Lo más impresionante es que, no sólo el término registrado por López Yepes no corresponde a ninguno de los enumerados por Urbano, sino que tampoco los vocablos usados por los indígenas contemporáneos concuerdan con los de la antigüedad. Con los mayas pasa algo semejante; pues, mientras los vocabularios de la colonia temprana nos presentan tres términos distintos como traducciones de " alma », los etnólogos modernos muestran sólo uno que, además, puede no concordar con ninguno de los citados por los evangelizadores del siglo XVI. También encontramos discrepancias en el número y el nombre de las " almas » antiguas y modernas de los quichés - antes una, ahora dos -, los mames - los nombres no concuerdan - y los mixtecos - uno de cuatro nombres se mantiene constante. Aun en náhuatl, donde el vocabulario de las almas tiende a ser menos mutable, el número de entidades reconocidas en la actualidad es generalmente dos, aunque también puede hablarse de tres e incluso cuatro. Lo más llamativo es que, en ocasiones existen más similitudes entre las concepciones anímicas de dos pueblos relativamente alejados que entre comunidades vecinas; esto sucede, por ejemplo, entre los nahuas de la Huasteca, la Sierra Norte de Puebla y el centro de Guerrero (ver Tabla 1). Sobre los huicholes, encontramos que, mientras algunos 
estudiosos hablan de tres entidades independientes y diferentes, otros se refieren a una sola pero con dos nombres y ubicaciones distintas. Quienes han trabajado entre los totonacas registran, por lo común, dos almas distintas; el problema es que, en ocasiones, sus nombres, cualidades y ubicaciones difieren considerablemente. Entre los chontales y los mames, se reporta el uso de dos términos referentes al alma que no se encuentran relacionados etimológicamente; el problema aquí es que ninguno de los autores menciona más de un alma. De modo semejante, los quichés y los mixes contemporáneos suelen tener, simultáneamente, concepciones anímicas diferentes (McLean 1984, p. 399; Schultze Jena 1947, p. 50; Lipp 1991, pp. 43-46; Schoehals y Schoehals 1965, p. 188; Hoogshagen y Halloren 1993, p. 262). Y así podríamos continuar la lista pasando por, prácticamente, todos los grupos indígenas de la región estudiada (ver Tabla 1).

Sin embargo, si analizamos con mayor detalle nuestros datos, podemos ver que los significados de los términos que correspondrían «alma », « ánima » y " espíritu » tienden a mantenerse constantes. En los diccionarios antiguos, la mayoría de las palabras asociadas a entidades anímicas pueden clasificarse, según sus sentidos, en tres grupos principales: 1 . Vocablos cuyo significado se refiere a elementos gaseosos - « aire », « viento », « aliento », « soplo », etc.; 2. Términos compuestos por raíces que significan « vida »;3. Palabras cuyo sentido es « corazón » o " estómago ». Y en algunos casos menos recurrentes, dichas palabras pueden también significar " sagrado » o « sobrenatural », " semejanza », « candela », « calor » o « irradiación » (ver Tabla 2). Pudiera pensarse que la recurrencia en los significados de los términos tratados sólo prueba que, para traducir conceptos cristianos, los frailes de distintas regiones se basaron en criterios semejantes; traduciendo textualmente « aliento » por « espíritu » y « vida » por « ánima ». No obstante, también hemos podido observar que, en los vocabularios modernos y los textos etnográficos contemporáneos, los significados de las « almas » suelen ser semejantes a los de la antigüedad. Los sentidos más recurrentes fueron por orden de importancia: "corazón, hígado o estómago », « aliento, soplo, viento », « sombra », " calor, luz, irradiación, brillo », « vida », « conocimiento », « mollera » $\mathrm{y}$ « divino o sagrado » (ver Tabla 3 ). Comparando estos datos con lo reportado por los etnólogos modernos, hemos podido observar que, salvo en algunos casos poco frecuentes, las diversas almas mesoamericanas pueden ser agrupadas en cuatro clases principales: almas-corazón, almas-aire, almas-calóricas y almas-sombra.

\section{Sobre LAS ALMAS-CORAZÓN}

Tal como se observa en la Tabla 3, el alma-corazón es, por mucho, la entidad anímica más presente e invariable de Mesoamérica. Entre las características que con mayor frecuencia se le asocian están la memoria, la vitalidad, el pensamiento, 
la voluntad, el carácter, el comportamiento moral, el valor, el destino, la afectividad, el conocimiento y, en menor medida, la sexualidad. Es común que se suponga que dicha entidad puede dejar el cuerpo en diversas circunstancias sin que ello implique necesariamente la muerte: 1 . Se dice que abandona el organismo durante el sueño para vagar libremente durante la noche; el recuerdo de sus experiencias es el contenido de los procesos onírico; 2 . Sale del cuerpo durante la embriaguez y el coito, siendo la sensación diversa del propio ser una consecuencia de la ausencia anímica; 3 . Puede igualmente desprenderse a causa de una caída o una fuerte impresión, o ser robada por brujos y entidades sobrenaturales; produciéndose en tales casos aquella patología llamada susto. Por último, podemos observar que en un número bastante grande de casos es esta entidad quien se supone va al mundo de los muertos tras el deceso de la persona (ver Tabla 4).

En lo que respecta a su forma, podemos mencionar que tanto las fuentes antiguas como las modernas se refieren a esta entidad bajo tres aspectos diferentes: un aire, una silueta antropomorfa de naturaleza etérea y un ser alado. Localizamos la creencia en aves del corazón entre los nahuas de Milpa Alta, Morelos y Puebla, los tzotziles, los tzeltales de Cancuc, los mixes y los lencas (Madsen 1960, p. 30; Lewis 1963, p. 278; Álvarez Heydenreich 1987, pp. 99-100; Fagetti 1996, pp. 104-106; Romero López 2003, p. 87; Guiteras Holmes 1965, p. 244; Pitarch 1996, p. 187; Figuerola 2005; Lipp 1991, p. 43; Chapman 1985, p. 204) ${ }^{4}$. Observamos elementos gaseosos vinculados al mismo órgano entre los nahuas de Morelos y Puebla, los otomíes, los totonacos, los huaves, los choles, los tzotziles y los chontales (Álvarez Heydenreich 1987, pp. 99-100; Fagetti 1996, p. 104; Galinier 1979, p. 429; 1990, p. 626; Silva 1972, p. 88; García y Oseguera 2001, p. 74; Whittaker y Warkentin 1965, pp. 88-89; Guiteras Holmes 1961, p. 296; Carrasco 1960, p. 110). Encontramos la creencia en almas antropomorfas ligadas al corazón entre los nahuas de la Sierra Negra, los mochós, los tzotziles, los tzeltales y los chontales (Romero López 2003, p. 87; García Ruiz 1987, p. 276; Page Pliego 2002, p. 178; Pitarch 1996, p. 188; Figuerola 2005; Carrasco 1960, p. 110$)^{5}$.

Sin embargo, esto no significa que tales formas sean excluyentes pues, cuando menos, entre los nahuas del siglo XvI, éstas parecen coexistir. En primer lugar, encontramos que, en las citas de los informantes nicaraos de Bobadilla sobre el yulio, se describe al corazón tanto como « algo que parece una persona » como bajo la imagen de un "aliento que sale por la boca » al momento de la muerte (Fernández de Oviedo y Valdés 1840, pp. 27-36). Al mismo tiempo, encontramos que, de acuerdo con Durán (1967, II, p. 54), aquello que se ofrendaba al sol en el sacrificio por cardioctomía era "el vaho »; lo que implicaría igualmente la presencia de algo gaseoso en el corazón ${ }^{6}$. En segundo lugar, el Códice Florentino (1950-1963, IX, p. 25) comenta sobre un ave conocido como yollotototl « ave del corazón » « vive en Teotlixco [Frente a los Dioses], hacia el mar del suroeste [...]. Se le llama ave del corazón. Así, aquellos hombres dicen que, cuando morimos, [el 
yollototot $]$ ] encarna nuestros corazones " ${ }^{7}$. Asimismo, conocemos un pasaje en el que, para señalar su ineptitud, los informantes de Sahagún (ibid., X, p. 25) indican que el mal pintor " tenía un pájaro dormido en su corazón ».

Por otro lado, encontramos entidades anímicas que, sin llamarse " corazón », se localizan o se concentran en el músculo cardíaco. Esta es, por ejemplo, la situación del čahçi:l, "sombra », de los mochós, el iwigalá, "aliento », de los rarámuris y el tyi $i$, « calor », de los chatinos (Tabla 3). Conocemos igualmente casos en los que el corazón es centro de más de un elemento anímico; esto es, por ejemplo, observable entre los otomíes - que ubican en un mismo órgano al nzahki y al ntâhi (Galinier 1979, p. 429; 1990, pp. 618-619, 622-626).

Por último, también, hemos visto que las almas-corazón no sólo radican en dicho órgano. Los tzutuhiles consideran que la sangre contiene $a k^{\prime} u x$ (Vallejo Reyna 2001, p. 152). Los tzotziles sitúan simultáneamente al ch'ulel en la punta de la lengua, el corazón, la sangre y el cuerpo entero (Gossen 1975, p. 450; Vogt 1969, p. 369; Guiteras Holmes 1961, p. 296). Para los tzeltales, aun cuando el ch'ulel se localice en el corazón, éste puede abandonar el cuerpo tanto por la boca como por la coronilla (Pitarch 1996, p. 187). Los chontales creen que el wahma kitine se ubica tanto en el aliento como en el corazón (Carrasco 1960, p. 110). Mientras que, en opinión de los choles, el ch'ulel « está en nuestros brazos, en nuestras piernas, en todo nuestro cuerpo » (Whittaker y Warkentin 1965, p. 89). Todo esto sin mencionar que tanto los tzotziles como los tzeltales piensan que el ch'ulel puede residir al mismo tiempo en el cuerpo humano y un lugar mítico, ya sea el Cielo o una « montaña sagrada » denominada Ch'iibal (Page Pliego 2002, p. 179; Pitarch 1996, p. 187) ${ }^{8}$.

Entre los indígenas oaxaqueños es común que el mismo vocablo que alude al corazón se refiera a otras zonas aledañas. El tiye de los chatinos significa « pecho, estómago, corazón » (Pride y Pride 2004, p. 189). El tsei de los chinantecos alude tanto al corazón como al pecho en general (Skinner y Skinner 2000, p. 359). Para los mixes, el término joot, del que deriva joot animi « alma », designa al mismo tiempo al hígado y al corazón (Schoehals y Schoehals 1965, pp. 211, 220, 276) ${ }^{9}$. Mientras que la raiz lajz de los zapotecos aparece tanto en lastoo " corazón », como en lasto guij « hígado » (Stubblefield y Miller de Stubblefield 1991, p. 158). $\mathrm{Al}$ mismo tiempo, podemos mencionar que, para los huaves, el principio vital se distribuye por el cuerpo a través de la sangre (García y Oseguera 2001, p. 71). Entre los mixes, encontramos dos tipos de creencias al respecto. Por un lado, estarían quienes consideran que el joot se localiza al mismo tiempo en la sangre, el corazón y los riñones, por el otro, tendríamos a quienes suponen que tal entidad se encuentra desdoblada en siete o catorce partes difundidas por todo el cuerpo (Lipp 1991, p. 44). Por último, podemos mencionar que, aparentemente, también los popolocas opinan que el alma-corazón se localiza en la sangre, pues uno de los medios más comúnmente usados para determinar su presencia o ausencia en el organismo es tomar el pulso (Abell 1970, p. 82). 
En otomí, la palabra que designa al corazón se refiere igualmente al estómago (Galinier 1990, pp. 623-626). Entre los purépechas existen tanto quienes ubican al mintzita en la cabeza como quienes lo sitúan en el corazón (Gallardo Ruiz 2005, pp. 83-90). Para los rarámuris, el alma que radica en el corazón se distribuye simultáneamente por todo el cuerpo, concentrándose en puntos vitales específcos (Merril 1992). En lo tocante a los huicholes, los datos disponibles parecen indicar que el alma-corazón no se limita a dicho órgano sino que, en ocasiones, parece confundirse con el kupúri « mollera » (Furst 1972, p. 11).

De este modo, tendríamos almas nombradas « corazón » que no se localizan exclusivamente en dicho órgano, almas que no son llamadas " corazón » y se ubican en el músculo cardíaco y corazones que contienen a más de una entidad anímica. Todo esto nos lleva a preguntarnos qué relación se establece entre el órgano ocupado y el elemento que lo ocupa. Pues, pareciera ser que, en ocasiones, las funciones anímicas se encuentran más vinculadas al órgano que a la sustancia que lo anima. Entre los otomíes, aquello que se asocia a la vitalidad, los sentimientos y el pensamiento es directamente el mbiii, " corazón o estómago », más que las entidades que en él residen (Galinier 1979, p. 429; 1990, pp. 623-624, 626). De igual manera, entre los chatinos, es al cresiya, " corazón », más que al tyi'i, al que se considera como centro de las emociones (Pride y Pride 1970, pp. 3, 11, 27, 87, 94, 189, 271, 297; Bartolomé y Barabas 1982, pp. 123-124, 132-135). Por último, tenemos que no se dice que, para los choles, el alma radique en el corazón, sin embargo se indica que este órgano es el centro de las emociones y el pensamiento (Aulie y Aulie 1998, pp. 20, 189).

Finalmente cabe mencionar que, aun si el alma-corazón es la entidad que se encuentra más difundida por nuestra región de estudio, ésta no tiene nada de específicamente mesoamericano. Pues, la encontramos tanto en los pueblos indígenas de Norteamérica - los cœur d'alène y los ojibwa, entre muchos otros (Elmendorf 1967, pp. 106-107; Vecsey 1983, pp. 59-60; McKeever Furst 1995, pp. 34-35; Hultkrantz 1953, p. 212) - como en los de la parte sur del continente (Greenway 1987, pp. 266, 269-272, 280) ${ }^{10}$.

La localización del alma en el corazón es tan frecuente que incluso la encontramos en el Occidente Medieval (Baschet 2000, p. 9).

\section{Sobre laS ALMaS-AIre}

Como ya lo ha señalado López Austin (1996, I, p. 257) el alma-aliento es, por mucho, el componente anímico que presenta mayores problemas para su identificación ${ }^{11}$. Para empezar, puesto que el alma-corazón puede también presentarse bajo la forma de un aire y que no se ubica exclusivamente en el músculo cardíaco, la simple mención de un elemento gaseoso no nos permite discernir, en todos los casos, de cuál de las dos se trata. Pudiera pensarse que, para los indígenas la 
respiración es producto de la acción del corazón o que, de algún modo, no haya diferencia entre pulmones y corazón. No obstante, podemos objetar que, aun cuando el corazón pueda vincularse a otros órganos vecinos, en ninguno de los casos conocidos se le confunde con los pulmones; y sólo en algunos pueblos norteños - como los huicholes y los rarámuris - se supone que la respiración se produce en el pericardio (Zingg 1982, pp. 312-313; Merril 1992, pp. 137-138).

En lo referente a sus cualidades y funciones, las informaciones procedentes de diversos grupos étnicos suelen ser poco constantes pues, salvo la voz, el sabor, el olor y la vitalidad, son pocas las funciones recurrentes y, en general, suelen confundirse con las que se atribuyen a otros componentes anímicos. Raras veces, la ubicación del aliento se encuentra definida en forma explícita, pudiendo ésta variar entre el hígado, o las ijadas, para los nahuas del siglo XvI, la parte baja del estómago, entre los chatinos, y el corazón o estómago, según los rarámuris y otomíes (López Austin 1996, I, p. 257; Bartolomé y Barabas 1982, pp. 123-124, 132-135; Merril 1992; Galinier 1990, pp. 618-619, 622-624, 626). Otra característica que, en ocasiones, puede ser atribuida a las almas-aliento es el poder separarse del cuerpo sin que ello implique necesariamente la muerte del sujeto. Entre los chatinos y los popolocas, se dice que son los « siete vientos » o el « aliento » quienes abandonan el organismo durante el susto, los zapotecos piensan que, sin excluir la circunstancia anterior, dicha entidad puede dejar el cuerpo durante la ebriedad y el desmayo ${ }^{12}$. Entre los rarámuris y los otomíes, se considera que es el alma-aire quien vaga libremente en el sueño y quien viaja al inframundo tras la muerte de la persona (Bartolomé y Barabas 1982, pp. 123-124, 132-135; Jäcklein 1974, p. 264; Butler 1997, pp. 266, 415; Merril 1992; Galinier 1979, 429; 1990, pp. 618-619, 622-624, 626).

Aun si vemos en la Tabla 5 que dicho elemento no ha sido registrado más que en unos cuantos grupos mesoamericanos, en ocasiones, algunas de las cualidades que le han sido atribuidas se encuentran presentes en un área sumamente vasta. Por ejemplo, la creencia en emanaciones patógenas producto de la muerte, de la trasgresión de las normas morales o asociadas a ciertos estados considerados como impuros, ha sido observada desde los opatas hasta los pueblos indígenas de Talamanca, Costa Rica; el problema es que, hasta donde sabemos, salvo los mixtecos, ninguno de tales grupos asocia estos gases a cualquiera de sus almas.

En relación con esta misma clase de componentes anímicos, encontramos a menudo la creencia en aires que deambulan por la tierra tras la muerte del individuo. Un informante huichol cuenta que, a veces, el viento que levanta las enaguas a las mujeres es « la vida de ese hombre [que acaba de morir] viendo si ella es como él la conoció » (Furst 1972, p. 40). Además de la entidad residente en el corazón o estómago, los mixes creen en la existencia de ciertas entidades, llamadas poh " aire ", que se separan del cuerpo tras la muerte y que, por medio de un ritual, se les incorpora a la sepultura para que residan en ella (Lipp 1991, p. 29) ${ }^{13}$. Para los tepehuas, los «vientos de la noche » son los difuntos que 
murieron asesinados (Williams García 1963, p. 197). Entre los borucas, se dice que « el viento que sopla en la noche es un alma en pena » (Stone 1949, p. 25). Cuando, entre los indígenas de los Tuxtlas, alguien se enferma después de un funeral «dicen que es el viento de difunto que le llega y se lo quiere llevar también » (Kelly 1956, pp. 71-72). Los chatinos creen que « al morir una persona, su tyi' $i$ abandona el cuerpo sufriendo un cambio cualitativo; se transforma en la lyumâ, la que podría ser definida como "alma de difunto", una parte de la cual queda en el panteón, mientras que la otra viaja al país de los muertos » (Bartolomé y Barabas 1982, p. 124). Entre los totonacas, cuando se despide al muerto se le dice « no vengas a espantar a tus hijos, a tu mujer. - Tú ya no eres más que un viento. - No vuelvas más » (Ichon 1973, p. 183) ${ }^{14}$.

Como en el caso del alma-corazón, parece ser que el concepto de alma-aliento no es exclusivo de los grupos mesoamericanos. Dicha entidad se encuentra ampliamente difundida por toda Norteamérica; incluso encontramos la asociación entre viento nocturno y almas de los muertos entre los cahuilla, los shoshone, los paiute, los ute, los tubatulabal, los navahos, los apaches de White Mountain y los ojibwa (Hultkrantz 1953, pp. 179-184; McKeever Furst 1995, pp. 150-152; Hooper 1920, p. 342; Reichard 1970, p. 34; Goodwin 1938, p. 36; Vecsey 1983, p. 60). En Sudamérica, tenemos con frecuencia la creencia en entidades anímicas gaseosas; tal es el caso del " alma » de los yauyos, el samay, " aliento », de los quechuas y el samama, " aliento » de los aymaras. Cuando menos, entre los yauyos, se piensa que dicha entidad puede manifestarse sobre la tierra como una sombra (Delgado Thays 1965, p. 21; Greenway 1987, pp. 279 280; Tschaupik 1968, pp. 158-159).

\section{Sobre laS ALMAS-SOMBRA}

Como vemos en la Tabla 6, no son más que unos cuantos grupos mesoamericanos en los que se ha registrado la creencia en elementos vitales denominados sombra. Debido a su mal conocimiento, la ubicación de tal elemento es pocas veces definida; no obstante, sabemos que ésta puede, cuando menos, oscilar entre la cabeza y el corazón. Y aun cuando sus funciones vitales sean poco claras y, en ocasiones, francamente reducidas, parece evidente que dicha entidad es pensada como indispensable para la vida. Pues, a veces, se supone que su separación del cuerpo a causa de una caída o susto es razón de enfermedad y muerte. Sin embargo, parece ser que su característica más recurrente es el encontrarse ligada al lugar en el cual se produce la muerte o se localiza el cuerpo después de los ritos funerarios correspondientes. Es común que se considere que, al tratarse de una muerte violenta, la sombra queda vagando sobre la tierra.

Aunque no contamos con muchos datos al respecto, sabemos que en algunos casos esta entidad puede encontrarse subordinada a otra alma. Entre los nahuas 
de las Sierras de Puebla y Zongolica, se cree que el ecahuil recibe su fuerza del tonalli, se encuentra unido al cuerpo por el tonalli y se mantiene en contacto con él en los momentos en que abandona el organismo (Duquesnoy 2001, pp. 443, 437; Rodríguez López 2000, p. 181); mientras que, para los tzeltales de Cancuc « es la sombra del ch'ulel y no otro ch'ulel» (Figuerola 2005, comunicación personal).

La creencia en almas-sombra se encuentra sumamente difundida por todo el septentrión americano. La encontramos entre los inuit, los atsine, los cherokee, los hidatsa, los pomo, los navajos, los eyak, los kwakiutl, los nootka, los hurón, los coyukan, los carrier, los atapascanos del oeste, los tlingit, los algonquinos, los cheyennes, los choctaw, los catawa, los dakota, los yumas, los maricopa, los huvasupai, los mohave, los apaches, los paiute y muchos más (Hultkrantz 1953, pp. 256-258, 304-305). En algunos casos, como el de los cheyennes, la sombra, tăsōōm, es pensada como un elemento que, además de tener funciones anímicas durante la vida, tiende a permanecer en el mundo de los vivos tras la muerte (Bird Grinnell 1972, p. 98). En Sudamérica la tenemos entre los aymaras, con el nombre de axayu, los jívaros, bajo el título de iwanch, y los campa (Tschaupik 1968, pp. 158-159; Brown 1981, p. 45; Delgado Thays 1965, p. 17; Weiss 1975). Lo interesante que, en estos casos, es también la sombra quien se supone queda vagando sobre la tierra tras la muerte del cuerpo.

\section{Sobre las aLmas calóricas}

La idea de un componente anímico con cualidades calóricas se encuentra presente en buen número de pueblos mesoamericanos. El problema es que, aunque vemos en la Tabla 7 que los elementos calóricos son pensados como fuente de vitalidad en distintos grupos étnicos, en casi ninguno de los casos estudiados tales entidades están dotadas de los mismos atributos que el muy conocido tonalli de los nahuas (ver López Austin 1996; Martínez González 2007). De hecho, es poco común que los investigadores consideren como «alma » al calor vital y, muchas veces, las cualidades que los nahuas atribuyen al tonalli, en otras regiones se asocian al « corazón »; entre otras cosas, es poco común que se le considere como algo individualizado.

Lo que sí parece claro es que tal elemento suele concentrarse en la sangre, la cabeza y el corazón. Los nahuas de Cuetzalan afirman explícitamente que la fuerza del tonalli es portada por la sangre (Aramoni 1990, p. 33), mientras que sus similares de Pajapan suponen que una hemorragia podría ser causa de la pérdida del tonalli (García de León 1969, p. 288). Los tzotziles hablan de la « fuerza de la sangre » (Guiteras Holmes 1961, p. 297). Para los mixtecos, «la sangre es el principio "caliente" vital [...] La falta de fuerza es atribuida a una débil circulación sanguínea » (Flanet 1977, pp. 103-104). Los chortís creen que « la sangre es 
el agente que mantiene al cuerpo caliente y que trasmite la fuerza a todas sus partes ». Es posible que sea a causa de su concentración en el corazón que los nahuas contemporáneos de Milpa Alta consideran que el yollotl es caliente durante la vida y frío tras la muerte (Madsen 1960, p. 167). Sus símiles de la Sierra Negra opinan que una de las doce partes del tonalli radica en el músculo cardíaco (Romero López 2006, comunicación personal). Los chatinos afirman que el tyi'i «calor » se localiza en este mismo punto (Bartolomé y Barabas 1982, p. 123). Mientras que los tzotziles y los tzeltales consideran que algunas personas tienen el corazón más caliente que otras (Gossen 1975, p. 449; Pitt-Rivers 1971, p. 12). Además de los mexicas prehispánicos, los nahuas y los teenek consideran que el alma-calor se concentra en la cabeza (Ponce de León 1965, pp. 125, 132; Lupo 2001, p. 358; Aramoni 1990, p. 35; Sánchez y Díaz de Rivera 1978, p. 221; Duquesnoy 2001, p. 420; Ariel de Vidas 2003, pp. 251-254; Alcorn 1984, p. 67).

Como en los casos anteriores, también se supone que el alma-calor puede abandonar el cuerpo durante el susto, el coito, la ebriedad y el sueño (López Austin 1996, pp. 234, 368). Aunque, en los documentos sobre los pames, no se explica qué tipo de entidad es la que se pierde durante el susto, es muy posible que se trate de un componente anímico parecido al tonalli. Pues, para el tratamiento de dicho mal, se recomienda el uso de "plantas calientes "; de modo que, habiéndose perdido el elemento calórico interno se debe recurrir a fuentes de calor externas (Chemin Bässler 1984, pp. 209-211). También, resulta claro que para los teenek y los quichés, el susto implica la pérdida de un elemento calórico, pues se supone que, en tales circunstancias « se siente un viento frío que entra por esa chimenea [de la coronilla] » y " la sangre se enfría mucho » (Ariel de Vidas 2003, p. 254; Adams 1952, p. 30; Marshall 1986, p. 126).

\section{Sobre almas poco USUALES}

A pesar de los elementos que tienden a mantenerse constantes en las concepciones anímicas mesoamericanas, debemos admitir la existencia de creencias que no corresponden, en modo alguno, a los principios clasificatorios expuestos con anterioridad. Según Ichon (1973, pp. 175-176), los totonacas de la Sierra creen en dos almas principales, una grande y otra pequeña: el alma grande se llama li-stakna " eso que hace vivir y crecer el cuerpo " y la pequeña li-katsin, cuyo sentido se asocia al conocimiento (Reid y Bishop 1974, p. 65). La primera de estas entidades es pensada como múltiple y difusa, dispersa por todo el cuerpo y concentrada en la coronilla, la sangre y todos los puntos en que se siente latir el pulso. La segunda, es única, se concentra en la cabeza y se supone que puede abandonar el cuerpo durante el sueño. Siendo que tales términos figuran en distintos vocabularios de totonaca, podemos considerar que estas creencias son las más difundidas (Aschman 1973, p. 3; Instituto lingüístico de Verano 1973, 
p. 161). En algunos pueblos quichés, se supone la existencia de dos entidades anímicas; una, llamada jajalmac, ubicada en la parte frontal del cuerpo y la otra, chajenel, situada en la espalda. El jajalmac, quien conoce el pecado y la tentación, puede desprenderse del cuerpo en tres circunstancias diferentes: durante el sueño, el susto y tras la muerte para viajar al inframundo. Por el contrario el chajenel se encarga de cuidar el cuerpo de los elementos nefastos que pudieran introducírsele, mientras la otra alma se encuentra ausente. Si el « espíritu guardián » dejara su puesto, el jajalmac simplemente se quedaría en el dominio de los sueños para siempre (McLean 1984, p. 399). Lo interesante es que, en ambos casos, estas ideas pueden coexistir con concepciones más mesoamericanas.

Otra idea poco recurrente en el territorio tratado es que la persona está dotada de almas buenas y almas malas que se disputan por orientar el comportamiento individual; esto es observable entre los chatinos y los mixes (Bartolomé y Barabas 1982, pp. 123, 134; Lipp 1991, pp. 43-46). Pudiera pensarse que esta clase de ideas es producto de la interpretación indígena de la noción occidental de « conciencia » o " ángel de la guarda ». Sin embargo, es preciso señalar que este tipo de creencias es frecuente en el norte de Sudamérica y el sur de Centroamérica. Así, por ejemplo, entre los quechuas, el término " estrella », que muchas veces se confunde con « ánimo », se asocia al destino personal. Se dice que todo mundo posee dos estrellas, una derecha y otra izquierda. La izquierda es femenina y malévola, la derecha, masculina y benévola. Se dice que la « estrella » está sobre el hombro (Greenway 1987, pp. 284-292). En el mismo sentido, Ferrero (2000, p. 202) indica que, para los pueblos costarricenses de origen sudamericano, de la familia lingüística macro-chibcha, toda persona posee un alma buena y otra mala (ibid.).

$\mathrm{Y}$, aunque todavía ignoramos el origen de las concepciones anímicas totonacas y quichés, la situación antes descrita nos obliga a interrogarnos sobre la naturaleza de los múltiples contactos e intercambios culturales que pudieron producirse en época prehispánica entre las diferentes regiones culturales de nuestro continente.

\section{SObRe LOS CONJUNTOS Y LAS FUNCIONES DE LAS ALMAS}

Hemos visto que, en la mayoría de los casos, las almas mesoamericanas pueden clasificarse en cuatro grupos principales; corazón, aliento, calor y sombra. No obstante, también hemos podido notar que la presencia de términos con sentidos similares no significa que estos se combinen de igual manera en los diferentes grupos indígenas. Tenemos, por ejemplo, la asociación corazón-caloraliento-sombra entre los mixtecos y los nahuas de la Sierra de Zongolica. Encontramos el conjunto corazón-calor-aliento entre los chatinos, y posiblemente entre los cuicatecos ${ }^{15}$. Es posible que la combinación corazón-calor- 
sombra exista entre los zoques; pues, aunque los datos sobre los componentes anímicos de este grupo son sumamente vagos, ubicamos tres conceptos que parecen encontrarse asociados a ellos ${ }^{16}$. La combinación corazón-aire se presenta entre los mazatecos, los zapotecos y, tal vez, los chinantecos ${ }^{17}$. Vemos el sistema corazón-calor entre los nahuas de la Huasteca, Guerrero y la Sierra Norte de Puebla, los teenek, los popolucas y los triquis. Tenemos el conjunto corazón-sombra entre los nahuas de la Sierra Norte de Puebla, los totonacas, los purépechas y los tzeltales. Observamos la idea de una entidad anímica unitaria alojada en el corazón (que, en ocasiones, puede ser múltiple o fragmentaria) entre los mayas yucatecos, los rarámuris, los tzotziles y los tojolabales. Por último, tenemos el caso descomunal de los kekchíes, para quienes el único componente anímico es la sombra (ver Tabla 3$)^{18}$.

En términos generales, las combinaciones más comunes fueron corazón/calor, corazón/sombra y corazón como entidad unitaria. Cabe notar que, pese a la diversidad de las creencias, en ninguno de los casos se registraron las combinaciones calor/sombra, calor/aliento o aliento/sombra; lo cual parece mostrar que, en casi todas estas creencias, es en torno al corazón que se construye el sistema. Al mismo tiempo, es poco común que se presente la creencia en el aliento y la sombra en un sólo grupo; pues, aunque esto parece existir tanto entre los nahuas como los mixtecos, entre los últimos, no hemos podido determinar si todos los componentes anímicos (" corazón », " calor ", " aire » y « sombra ») se presentan en una misma comunidad.

Por otro lado, nos encontramos ante el problema de que el hecho de que una determinada creencia no haya sido registrada no significa necesariamente que no exista. Pues, siempre es posible que, habiéndose visto opacado por un término dominante, el componente más sutil haya pasado desapercibido a los ojos del investigador. Un ejemplo de ello es la ya mencionada creencia en la « sombra » de los nahuas de la Sierra Norte de Puebla, pues ésta no fue considerada sino hasta que Signorini y Lupo (1989) y Duquesnoy (2001) comenzaron a plantearse las preguntas correctas.

Como se observa en la Tabla 3 , casi todos los pueblos indígenas de la zona tratada consideran que alguno de sus componentes anímicos puede separarse del cuerpo durante ciertas condiciones (como el sueño, el susto, la ebriedad y el coito) sin que ello implique necesariamente la muerte de la persona. Pudiera pensarse, a partir de esto, que las concepciones anímicas mesoamericanas siguen la misma división básica que la planteada por Hultkrantz (1953, pp. 51-54) y Rivière (1987, p. 428) - free soul y body soul o internal soul y external soul. Sin embargo, nosotros observamos que, en Mesoamérica, las cuatro clases de almas son susceptibles de dejar el cuerpo durante la vida. Y, en algunos casos, se considera que todas ellas se separan del organismo; esto sucede, por ejemplo, entre los teenek de San Luís Potosí, los purépechas y los chontales (Alcorn 1984, p. 67; Gallardo Ruiz 2005, pp. 83-90; Carrasco 1960, p. 110). En otros grupos, como los otomíes, no resulta 
claro cual de las dos almas es la que desprende del cuerpo durante la vida (Galinier 1990, pp. 623-626; Dow 1975, p. 62). En otros más, como los chatinos, se cree que lo que se separa durante el sueño no es lo mismo que lo que deja el cuerpo durante el susto (Pride y Pride 1970, pp. 3, 11, 27, 87, 94, 189, 271, 297; Bartolomé y Barabas 1982, pp. 123-124, 132-135).

Algo semejante sucede con aquella patología conocida en español como mal de ojo. Pues, mientras los totonacas y los triquis consideran que ésta es producida por la introducción de un aire o sombra extraño, los mayas yucatecos, los teenek y los pames atribuyen esta cualidad al exceso de calor, y los nahuas de la Sierra Negra a la posesión de un corazón amargo. De igual manera, podemos ver en la Tabla 3 que tanto la sombra como el calor y el corazón (y tal vez el aliento) son susceptibles de condicionar el destino de la persona y los tres se encuentran distribuidos por el cuerpo.

También sabemos que, en un gran número de casos, se considera que las personas (o algunas de ellas) se encuentran dotadas de una coesencia, preferentemente animal, conocida como nahual o tonal en la literatura especializada. Como es sabido, es el hecho de compartir un alma lo que hace que ambos seres tengan destinos interdependientes. Lo que aquí nos interesa es que las clases de entidades anímicas compartidas suelen ser sumamente variables. Para los tzotziles, los tzeltales, los jacaltecos, los chuj y los tojolabales es el alma-corazón lo que une al hombre con su nahual (Guiteras Holmes 1961, pp. 303, 306; Köhler 1995, p. 22; Figuerola 2005; La Farge y Byers 1931, p. 133; La Farge 1947, p. 152; Ruz 1983, pp. 425-431); dicha función es cubierta por el aliento o la sombra entre los otomíes (Galinier 1990, pp. 429, 625-626) y el alma calórica o la sombra entre los nahuas de la Sierra Norte de Puebla, los zoques y los mixtecos (Signorini y Lupo 1989 , p. 57; Duquesnoy 2001, p. 251; Wonderly 1946, p. 98; Flanet 1977, p. 110).

Así, si consideramos que las cuatro entidades anímicas pueden ubicarse en el corazón y todo el cuerpo, que las cuatro se separan durante el susto y que todas ellas pueden servir como vínculo con el nahualli, podemos concluir que lo que tiende a mantenerse constante no son las almas en sí (como conjunto establecido de unidades estructuradas, formas, atributos y funciones), sino un esquema anímico, constituido en torno al corazón, en el que las cualidades y funciones de sus componentes se intercambian y recombinan dentro de límites más o menos finitos, eventualmente perpetrados por ideas procedentes de regiones vecinas. $\mathrm{Si}$ a esto añadimos que no siempre ha sido fácil reconocer a los diferentes componentes anímicos en un mismo grupo étnico y que, en algunos casos, un alma puede ocultarse en otra, valdría la pena preguntarse si, en realidad, no se trata de entidades anímicas diferentes sino de aspectos diversos de un alma compleja y dinámica en la que las partes pueden conllevar diversas cualidades del todo.

Las similitudes con regiones aledañas no implican que las concepciones anímicas mesoamericanas no sean en algunos casos claramente distinguibles. Un ejemplo de ello es el de las ideas sobre el alma de los bribris y cabecares de 
Talamanca; donde, aun si existe un alma-aire, se suele suponer que las entidades principales se ubican en los ojos. El alma del ojo derecho es quien viaja al inframundo después de la muerte y se reintegra a un nuevo ser tras su purificación. La del ojo izquierdo es como el fantasma de la persona, que se queda sobre la tierra hasta que se hayan efectuado las ceremonias funerarias secundarias; es esta misma entidad quien se separa del cuerpo en el sueño y el susto. También se suele pensar que cada órgano posee su propia alma y aliento vital, existiendo en tales casos hasta ocho entidades anímicas (Bozzoli 2006, comunicación personal; Guevara 2006, comunicación personal).

A pesar de que ya se ha dicho que la información disponible sobre las entidades anímicas no siempre es suficiente quisiéramos, aunque sea de manera hipotética, presentar el esquema bajo el cual se habrían de estructurar los diferentes modelos anímicos.

\section{En bUSCA de un ESQUema aníMIICO MESOAMERICANo}

Si pensamos que algunos de los componentes aquí identificados han desaparecido bajo la influencia de sistemas de pensamiento exógenos y que, en otros casos, estos elementos suelen camuflarse bajo almas más vistosas, es posible afirmar que, cuando menos idealmente, nuestro esquema debería contener a las cuatro entidades aquí citadas más aquella materia dura y pesada que constituye el continente corporal. Y, aunque sus características y funciones pueden confundirse e intercambiarse, existen algunos elementos que tienden a caracterizar a cada una de las partes del complejo anímico que aquí esbozamos.

El corazón es la parte del individuo que sobrevive al deceso del sujeto, la sombra - en ocasiones subordinada al corazón-permanece sobre la tierra mientras este realiza su viaje al inframundo, el aliento y el calor infunden vitalidad a la persona. Si a esto sumamos que muchas veces, en el pensamiento mesoamericano, el cuerpo se encuentra asociado a la tierra, podemos ver que nuestro sistema anímico guarda una estructura semejante a la planteada en el mito del Quinto Sol ${ }^{19}$.

De acuerdo con lo que menciona el Códice Florentino (I 84; VII 3-8) - sin duda, una de las versiones más completas - para convertirse en sol y luna, Nanahuatl y Tecciztecatl debieron arrojarse a una enorme hoguera. Al cabo de un tiempo, los dos personajes emergieron del inframundo bajo sus nuevas formas, deplazándose por el cielo hasta llegar al cenit. En dicho punto, ambos cuerpos celestes se detuvieron. Después de una breve discusión, los dioses, que entonces se encontraban sobre la tierra, decidieron sacrificarse ofrendándole al sol sus corazones. Tras haberse dado cuenta de que este último acto no había bastado para causar su movimiento, Ehecatl se puso a soplar logrando con ello que los astros se desplazaran. 
En primer lugar observamos que es precisamente el calor de la hoguera - semejante al calor anímico - quien produce la transformación de los dioses en astros, de la noche en día y procura el impulso inicial que lleva al sol y a la luna del inframundo al senit. En segundo, vemos al viento - análogo al alma-aliento como el elemento que produce el tránsito del sol a través del cielo. De tal manera que, si consideramos que es precisamente el corazón quien, en la vida y la muerte, imita el recorrido diario del sol pasando del inframundo a la tierra y de la tierra al inframundo, podemos observar que la función de la sombra sería semejante a la de la luna; pues, es esta parte quien imitando el movimiento del anterior se presenta sobre la tierra mientras este se encuentra en el inframundo.

\section{Algunas Reflexiones finales}

Como hemos visto a lo largo del presente trabajo, las concepciones anímicas mesoamericanas parecen ser mucho más variables que otros elementos de la cosmovisión. Algunas de tales divergencias - sobre todo las que se refieren a los nombres de las almas - pueden atribuirse a la influencia que el cristianismo y la cultura mestizo-occidental han tenido sobre la mentalidad indígena. Otras - como la presencia o ausencia de una cierta entidad - pueden achacarse al mayor o menor talento y capacidad de los distintos investigadores que han recogido los datos. Mas existen ciertas variaciones - como la atribución de una misma función a dos entidades diferentes dentro de un mismo grupo - que no parecen responder más que la propia elasticidad de las creencias en torno al alma, las cuales correspondiendo a aspectos íntimos de la vida, se encuentran sumamente expuestas a la interpretación individual. La falta de comunicación entre las distintas comunidades de un mismo grupo étnico, la pérdida de las visiones dogmáticas controladas por las Iglesias prehispánicas y un mayor o menor intercambio de ideas con grupos con los que antes no se estaba en contacto deben haber provocado que en diversas localidades se gestaran muy particulares concepciones anímicas a partir de la combinación diversa de las mismas cualidades y funciones.

En términos generales, las entidades anímicas mesoamericanas pueden clasificarse en cuatro clases principales: almas-corazón, almas-aliento, almas-sombra y almas calóricas. Sin embargo, hemos podido observar que los conjuntos anímicos suelen estructurarse de modos muy diversos. Los atributos, ubicaciones y funciones que se les asocian son, en ocasiones, muy variables. Y, en la mayoría de los casos, se trata de creencias sumamente generalizadas que también se presentan en otras zonas del continente; entre ellas el área Andina y Norte América. Sin embargo esto no significa que no exista un núcleo duro de las concepciones anímicas mesoamericanas sino simplemente que, para encontrarlo, es necesario excavar mucho más profundo en la concepción indígena de la persona. 
Entre las escasas cualidades y funciones que parecen mantenerse más constantes podemos mencionar las siguientes: 1. El número de entidades anímicas por persona suele oscilar entre uno y cuatro, siendo uno y dos las cifras más recurrentes. 2. Aunque una misma alma puede ocupar más de un órgano y un órgano alojar a más de un alma, encontramos que los centros anímicos más importantes suelen ser el corazón, el estómago, el hígado, la cabeza, la sangre y, en raras ocasiones, la lengua y los riñones. Cabe resaltar a este respecto la escasa importancia acordada a órganos vitales como los pulmones y los intestinos. 3. Independientemente de las formas que se le atribuyan, el alma-corazón suele ser pensada como responsable de la mayoría de las funciones intelectuales, la vitalidad, el valor y el destino. Es dicha entidad quien se supone viaja al inframundo tras el deceso del cuerpo. 4. El alma-aire, que como hemos dicho es sumamente difícil de identificar, parece ser mucho más variable que el alma-corazón; pudiendo en muchos casos confundirse con alguna de las manifestaciones de la primera. Entre las pocas funciones que tienden a mantenerse constantes encontramos las de producir la voz, el sabor, el olor y la vitalidad. 5. Del alma-sombra sólo se mantiene constante la idea de que es bajo dicha forma que los difuntos suelen figurar sobre la tierra. 6. Aun si el alma calórica es bien conocida entre los nahuas, en la mayoría de los casos tratados se le considera como un elemento vital cuyas funciones poco se relacionan con las características individuales. *

\footnotetext{
* Manuscrit reçu en mars 2007, accepté pour publication en juin 2007.
} 
TABLA 1 - Divergencias en las concepciones animicas

\begin{tabular}{|c|c|c|c|c|c|c|}
\hline $\begin{array}{l}\text { Náhuatl } \\
\text { antiguo }\end{array}$ & $\begin{array}{l}\text { Náhuatl } \\
\text { moderno }\end{array}$ & $\begin{array}{l}\text { Náhuatl } \\
\text { moderno }\end{array}$ & $\begin{array}{l}\text { Náhuatl } \\
\text { moderno }\end{array}$ & $\begin{array}{l}\text { Náhuatl } \\
\text { moderno }\end{array}$ & $\begin{array}{l}\text { Náhuatl } \\
\text { moderno }\end{array}$ & $\begin{array}{l}\text { Náhuatl } \\
\text { moderno }\end{array}$ \\
\hline $\begin{array}{l}\text { Tonalli } \\
\text { Teyolia } \\
\text { Ihiyotl } \\
\text { (I.ópez } \\
\text { Austin 1996) }\end{array}$ & $\begin{array}{l}\text { Yollo } \\
\text { Sewalli } \\
\text { Tona } \\
\text { (Rodriguez } \\
\text { González 2002; } \\
\text { Chanoux 1989) }\end{array}$ & $\begin{array}{l}\text { Noganematzin } \\
\text { Tlamachiliz } \\
\text { (Fagetti 1996) }\end{array}$ & $\begin{array}{l}\text { Yolo } \\
\text { Tona } \\
\text { (Sandstrom 1991; } \\
\text { Goloubinoff 1994; } \\
\text { Sánchez y Diaz 1978; } \\
\text { Aramoni 1990) }\end{array}$ & $\begin{array}{l}\text { Yolo } \\
\text { Ecahuil } \\
\text { (Signorini y } \\
\text { Lupo 1989) }\end{array}$ & $\begin{array}{l}\text { Yolo } \\
\text { Tona } \\
\text { Ecahuil } \\
\text { (Duquesnoy } \\
\text { 2001) }\end{array}$ & $\begin{array}{l}\text { Yolo } \\
\text { Tonalli } \\
\text { Ecahuil } \\
\text { lhiyotl } \\
\text { (Rodriguez } \\
\text { López 2000) }\end{array}$ \\
\hline
\end{tabular}

\begin{tabular}{|l|l|l|l|}
\hline Otomi antiguo & Otomí antiguo & Otomí moderno & Otomi moderno \\
\hline $\begin{array}{l}\text { Manmurey } \\
\text { Atetite }\end{array}$ & Hioya & Nzaki & Ndähi \\
Nóhia & Nópez Yepes 1826) & Huste \\
Na ihiphi & (Galinier 1990) & (Hernández Cruz et al. 2004) \\
(Urbano 1990) & & & \\
\hline
\end{tabular}

\begin{tabular}{|l|l|l|}
\hline Maya antiguo & Maya moderno & Maya moderno \\
\hline $\begin{array}{l}\text { Ik } \\
\text { Cuxtal }\end{array}$ & Pixan & $\begin{array}{l}\text { Ool } \\
\text { (Güenes Pineda 2000) } \\
\text { (Diccionario maya Cordemex 1980; } \\
\text { Ciudad Real 1995) }\end{array}$ \\
\hline
\end{tabular}

\begin{tabular}{|l|l|}
\hline Mixteco antiguo & Mixteco moderno \\
\hline Deye ni nanahanut & Anima yo \\
Sadzatacuìahayniyodza & Sombra \\
Ini & Tono \\
Sasite huitachi, sasite huindodzo, tachi niaha & Tachi \\
(Alvarado 1962) & (Flanet 1977; Romney y Romney 1973; Mak 1959; Beaty de \\
& Farris 2002) \\
\hline
\end{tabular}

\begin{tabular}{|l|l|l|}
\hline Quiché antiguo & Quiché moderno & Quiché moderno \\
\hline $\begin{array}{l}\text { Cazlibal } \\
\text { (Basseta 2005) }\end{array}$ & $\begin{array}{l}\text { Jajalmac } \\
\text { Chajenel } \\
\text { (McLean 1984) }\end{array}$ & $\begin{array}{l}\text { Ánima } \\
\text { (Schultze Jena 1947) }\end{array}$ \\
\hline Mam antiguo & Mam moderno & Mam moderno \\
\hline $\begin{array}{l}\text { Altzil } \\
\text { (Reynoso 1916) }\end{array}$ & $\begin{array}{l}\text { Nawal } \\
\text { (Tedlock 1982) }\end{array}$ & $\begin{array}{l}\text { Pixan } \\
\text { (Thompson 1927-1932) }\end{array}$ \\
\hline
\end{tabular}

\begin{tabular}{|l|l|}
\hline Huichol moderno & Huichol moderno \\
\hline Kupurio Jyari & Cerebro \\
(Furst 1972; Zing 1982) & Corazón \\
& Higado \\
(Weigand y García 1992) \\
\hline
\end{tabular}

\begin{tabular}{|c|c|}
\hline Totonaca moderno & Totonaca moderno \\
\hline $\begin{array}{l}\text { Alma } \\
\text { Sombra } \\
\text { (Córdova Olivares 1990) }\end{array}$ & $\begin{array}{l}\text { Li-stakna } \\
\text { Li-katsin } \\
\text { (Ichon 1973) }\end{array}$ \\
\hline Chontal moderno & Chontal moderno \\
\hline $\begin{array}{l}\text { Walmma kitine } \\
\text { (Carrasco 1960) }\end{array}$ & $\begin{array}{l}\text { Pixan } \\
\text { (Keller y Luciano 1997) }\end{array}$ \\
\hline
\end{tabular}


TABLA 2 - Alma, ánima y espíritu en los vocabularios antiguos

\begin{tabular}{|c|c|c|c|}
\hline Grupo étnico & $\begin{array}{l}\text { Número } \\
\text { de entidades }\end{array}$ & Términos empleados en la traducción & Fuente \\
\hline Maya & 3 & $\begin{array}{l}\text { 1. Ik" " viento " } \\
\text { 2. Cuxtal " vivir, tener uso de razón, tener juicio " } \\
\text { 3. Pixan " cosa que está cubierta [...] dichoso, afortu- } \\
\text { nado, beato, felice y bienaventurado ", " vivo, des- } \\
\text { pierto " }\end{array}$ & $\begin{array}{l}\text { Diccionario maya Cordemex } 1980 \\
\text { Ciudad Real } 1995\end{array}$ \\
\hline Tzeltal & 2 & $\begin{array}{l}\text { 1. Caghtsghib " candela " } \\
\text { 2. Chulel " suerte, dicha, ventura " « divino, sagrado, } \\
\text { santo" }\end{array}$ & Ara 1986 \\
\hline Pocomchi & 3 & $\begin{array}{l}\text { 1. Bebal } \\
\text { 2. Nach " semejanza; asemejar, imitar " } \\
\text { 3. Uxlab « aliento " }\end{array}$ & Morán y Zúñiga 1991 \\
\hline Quiché & 1 & Cazlibal « animar, dar vida » & Basseta 2005 \\
\hline Mam & 1 & Altzil « corazón o estómago " & Reynoso 1916 \\
\hline Cakchiquel & 1 & $\begin{array}{l}\text { 1. Jazlibal de jazlem « vida " } \\
\text { 2. Jux « corazón } »^{20}\end{array}$ & Guzmán 1989 \\
\hline Huasteco & 1 & $\begin{array}{l}\text { 1. Ehatal de eat " vivir " } \\
\text { 2. Elol " alma de los muertos ", " palomilla " }\end{array}$ & Tapia Zenteno 1985 \\
\hline Náhuatl & 4 & $\begin{array}{l}\text { 1. Yolia de yoli, "vivir" } \\
\text { 2. Tonalli de tona, "irradiar" } \\
\text { 3. Thiyotl " aliento" } \\
\text { 4. Ehecatl " viento" }\end{array}$ & Molina 2000 \\
\hline Matlatzinca & 1 & Imbotuyaa " corazón » & Basalenque 1975 \\
\hline Otomí & 4 & $\begin{array}{l}\text { 1. Manmuey " estómago, corazón" } \\
\text { 2. Atitete de te "vida " } \\
\text { 3. Nohia " aliento" } \\
\text { 4. Na ihiphi, tal vez, derivado de la misma raiz } \\
\text { náhuatl que se usa para ihiyotl }\end{array}$ & Urbano 1990 \\
\hline Otomi & 1 & Hioyá de hyáha " vahear" & López Yepes 1826 \\
\hline Zapoteco & 2 & $\begin{array}{l}\text { 1. Pée o penepaa « aliento " } \\
\text { 2. Lachi o lachitaoni « corazón" } \\
\end{array}$ & Córdoba 1987 \\
\hline Mixteco & 4 & $\begin{array}{l}\text { 1. Deje ni nanahanum "alma que [a]parece de } \\
\text { noche" } \\
\text { 2. Sadzatacuñahayniyodza } \\
\text { 3. Ini " calor, corazón" } \\
\text { 4. Sasite huitachi, sasite huindodzo, tachi ñaha }\end{array}$ & Alvarado 1962 \\
\hline Purépecha & $2\left(i^{3} ?\right)$ & $\begin{array}{l}\text { 1. Mintzita " corazón "; mintzitaqua } \\
\text { " aliento, huelgo, resuello" } \\
\text { 2. Tziperahperi } \\
\text { 3. Hiretaqua " aliento, huelgo, resuello" }\end{array}$ & Gilberti 1989-1997 \\
\hline
\end{tabular}


TABLA 3 - Entidades anímicas en pueblos indigenas contemporáneos de Mesoamérica y zonas vecinas ${ }^{21}$

\begin{tabular}{|c|c|c|c|c|c|c|}
\hline Grupo étnico & $\mathrm{N}$ & Nombre & Ubicación & Características & $\begin{array}{l}\text { Fntidad que va } \\
\text { al inframundo }\end{array}$ & Fuente \\
\hline Pápago & 1 & Loxachak & & $\begin{array}{l}\text { Elemento sólido, centro de los } \\
\text { procesos intelectuales }\end{array}$ & Loxachak & $\begin{array}{l}\text { Fontana } 1989 \text {, } \\
\text { pp. } 307-311\end{array}$ \\
\hline Rarámuri & 1 & $\begin{array}{l}\text { Iwiga de hi " respi- } \\
\text { rar" }\end{array}$ & $\begin{array}{l}\text { Corazón, todo el } \\
\text { cuerpo }\end{array}$ & $\begin{array}{l}\text { Centro de los procesos intelectua- } \\
\text { les. Entidad divisible que se des- } \\
\text { prende del cuerpo durante el } \\
\text { sueño }\end{array}$ & Iwiga & $\begin{array}{l}\text { Bennett y Zingg } \\
1935 \text {, pp. 323-324; } \\
\text { Wheeler 1998, p. } 97 \text {; } \\
\text { Merrill } 1992\end{array}$ \\
\hline Huichol & 3 & & $\begin{array}{l}\text { 1. Cerebro } \\
\text { 2. Corazón } \\
\text { 3. Higado }\end{array}$ & $\begin{array}{l}\text { 1. Centro de la razón } \\
\text { 2. Centro de la vitalidad, de la } \\
\text { memoria, el conocimiento y las } \\
\text { emociones } \\
\text { 3. Centro de la vitalidad fisica y } \\
\text { las emociones }\end{array}$ & & $\begin{array}{l}\text { Weigand y Garcia } \\
1992 \text {, p. } 220\end{array}$ \\
\hline Huichol & 1 & $\begin{array}{l}\text { Kupíri « mollera " o } \\
\text { iyari « corazón " }\end{array}$ & Cabeza y corazón & $\begin{array}{l}\text { Centro de la vitalidad y las } \\
\text { funciones intelectuales. Entidad } \\
\text { que se desprende durante el susto } \\
\text { o cl sueño }\end{array}$ & Kupiri & $\begin{array}{l}\text { Furst } 1972 \text {, pp. } 7-36 \text {; } \\
\text { Zingg } 1982 \text {, pp. } 312 \text { - } \\
313\end{array}$ \\
\hline Purépechas & 2 & $\begin{array}{l}\text { 1. Mintzita " cora- } \\
\text { zón" } \\
\text { 2. Zuanda « som. } \\
\text { bra " }\end{array}$ & $\begin{array}{l}\text { 1. Corazón, cabeza, } \\
\text { sangre y todo el } \\
\text { cuerpo } \\
\text { 2. Cabeza }\end{array}$ & $\begin{array}{l}\text { 1. De ella dependen el valor, el } \\
\text { ánimo, la vitalidad } \\
\text { 2. Entidad que tras la muerte se } \\
\text { separa del cuerpo para vagar } \\
\text { sobre la tierra algún tiempo y } \\
\text { disiparse eventualmente } \\
\text { Ambas entidades pueden sepa- } \\
\text { rarsedelcuerpoduranteelsusto }\end{array}$ & $\begin{array}{l}\text { Mintzita } \\
\text { transformada } \\
\text { en tziperah- } \\
\text { peri«aire" }\end{array}$ & $\begin{array}{l}\text { Gallardo Ruiz } 2005 \text {, } \\
\text { pp. } 83-90\end{array}$ \\
\hline Otomi & 2 & $\begin{array}{l}\text { 1. Nzaki « vida " } \\
\text { 2. Ndähi « aire" }\end{array}$ & Estómagoocorazón & $\begin{array}{l}\text { 1. Fuerza vital compartida por } \\
\text { todoloviviente } \\
\text { 2. Alma-soplo que se separa } \\
\text { duranteelsueño }\end{array}$ & Ndähi & $\begin{array}{l}\text { Galinier } 1990 \text {, } \\
\text { pp. } 623-626 \text {; } \\
\text { Dow } 1975 \text {,p. } 62\end{array}$ \\
\hline Otomi & 2 & $\begin{array}{l}\text { 1. Ndahi " aire" } \\
\text { 2. Huste " espiritu " }\end{array}$ & & & & $\begin{array}{l}\text { Hernández Cruz et } \\
\text { al. } 2004\end{array}$ \\
\hline Totonaca & 2 & $\begin{array}{l}\text { 1. Almao } \\
\bar{a} \text { 'nimaj } \\
\text { 2. Sombra }\end{array}$ & 1. Corazón & $\begin{array}{l}\text { 1. Sesepara duranteelsueno } \\
\text { 2. Fuerza interior que se irradia } \\
\text { comomaldeojo }\end{array}$ & Alma & $\begin{array}{l}\text { Córdova Olivares } \\
1990 \text {, p. 25; Aschman } \\
1973 \text {,pp. } 3,14\end{array}$ \\
\hline Totonaca & 2 & $\begin{array}{l}\text { 1. Li-stakna" esoque } \\
\text { hace vivir y crecer el } \\
\text { cuerpo" } \\
\text { 2. Li-staksinaso- } \\
\text { ciada a " conoci- } \\
\text { miento" }\end{array}$ & $\begin{array}{l}\text { 1. Lasangre } \\
\text { 2. La cabeza }\end{array}$ & $\begin{array}{l}\text { 1. Está asociada a la vitalidad y el } \\
\text { destino } \\
\text { 2. Es el principio del conoci- } \\
\text { miento que abandona el cuerpo } \\
\text { durante el sueño }\end{array}$ & & $\begin{array}{l}\text { Ichon } 1973 \text {, p. } 176 ; \\
\text { Reid y Bishop 1974, } \\
\text { p. } 65 \text {; Aschman 1973, } \\
\text { p. } 3 \text {; Instituto linginis- } \\
\text { tico de Verano } 1973 \text {, } \\
\text { p. } 161\end{array}$ \\
\hline $\begin{array}{l}\text { Náhuatl de } \\
\text { Huachi- } \\
\text { nango }\end{array}$ & 3 & $\begin{array}{l}\text { 1. Yolo } \\
\text { 2. Senalli } \\
\text { 3. Tona } \\
\end{array}$ & $\begin{array}{l}\text { 1. Corazón } \\
\text { 2. Sombra } \\
\text { 3. Todoelcuerpo }\end{array}$ & $\begin{array}{l}\text { Parece haber una confusión entre } \\
\text { tona y sewalli. Ver Chamoux } \\
(1989,303-310)\end{array}$ & Yolo & $\begin{array}{l}\text { Rodriguez González } \\
2002 \text {, p. 131; Cha- } \\
\text { moux } 1989\end{array}$ \\
\hline $\begin{array}{l}\text { Náhuatl } \\
\text { Valle de Pue- } \\
\text { bla }\end{array}$ & 2 & $\begin{array}{l}\text { 1. Noganehmatzin, de } \\
\text { "ánima" } \\
\text { 2. Tlamachiliz de } \\
\text { machiotl " conoci- } \\
\text { miento" }\end{array}$ & $\begin{array}{l}\text { 1. Corazón } \\
\text { 2. Todoelcuerpo }\end{array}$ & $\begin{array}{l}\text { 1. Centro de la vida, las emocio- } \\
\text { nes y los sentimientos. Abandona } \\
\text { clcuerpoduranteelsueño } \\
\text { 2. Fuera vital que puede per- } \\
\text { derseduranteelespanto }\end{array}$ & $\begin{array}{l}\text { Noganeh- } \\
\text { matzin }\end{array}$ & $\begin{array}{l}\text { Fagetti } 1996 \text {, } \\
\text { pp. } 76-87\end{array}$ \\
\hline $\begin{array}{l}\text { Náhuatl } \\
\text { Huasteca }\end{array}$ & 2 & $\begin{array}{l}\text { 1. Yolo } \\
\text { 2. Tona }\end{array}$ & $\begin{array}{l}\text { 1. Corazón } \\
\text { 2. Todoelcuerpo }\end{array}$ & $\begin{array}{l}\text { 1. Centrodela vida } \\
\text { 2. Fuerza vital y conciencia indi- } \\
\text { vidual }\end{array}$ & Yolo & $\begin{array}{l}\text { Sandstrom } 1991 \text {, } \\
\text { pp. } 258-259\end{array}$ \\
\hline $\begin{array}{l}\text { Náhuatl de } \\
\text { Guerrero }\end{array}$ & 2 & $\begin{array}{l}\text { 1. Yolo } \\
\text { 2. Tona }\end{array}$ & $\begin{array}{l}\text { 1. Corazón } \\
\text { 2. Todoelcuerpo }\end{array}$ & $\begin{array}{l}\text { 1. Centro del pensamiento y las } \\
\text { emociones } \\
\text { 2. Fuerza vital y centro de pensa- } \\
\text { miento que se desprende durante } \\
\text { elsueno }\end{array}$ & Yolo & Goloubinoff 1994 \\
\hline
\end{tabular}




\begin{tabular}{|c|c|c|c|c|c|c|}
\hline $\begin{array}{l}\text { Náhuatl } \\
\text { Sierra Norte } \\
\text { Puebla }\end{array}$ & 2 & $\begin{array}{l}\text { 1. Yolo } \\
\text { 2. Tona }\end{array}$ & $\begin{array}{l}\text { 1. Corazón } \\
\text { 2. Todoclcuerpo }\end{array}$ & $\begin{array}{l}\text { 1. Centro del pensamiento y las } \\
\text { emociones } \\
\text { 2. Fuerza vital y centro de pensa- } \\
\text { miento que se separa durante el } \\
\text { sueño }\end{array}$ & Yolo & $\begin{array}{l}\text { Sánchez y Diaz 1978; } \\
\text { Aramoni Abbat } 1990\end{array}$ \\
\hline $\begin{array}{l}\text { Náhuatl } \\
\text { Sierra Norte } \\
\text { Puebla }\end{array}$ & 2 & $\begin{array}{l}\text { 1. Yolo } \\
\text { 2. Ecahuil }\end{array}$ & $\begin{array}{l}\text { 1. Corazón } \\
\text { 2. Todoelcuerpo }\end{array}$ & $\begin{array}{l}\text { 1. Centro del pensamiento y las } \\
\text { emociones } \\
\text { 2. Fuerza vital y centro de pensa- } \\
\text { miento que se desprende durante } \\
\text { elsueño }\end{array}$ & Yolo & $\begin{array}{l}\text { Signoriniy Lupo } \\
1989\end{array}$ \\
\hline $\begin{array}{l}\text { Náhuatl } \\
\text { Sierra Norte } \\
\text { Puebla }\end{array}$ & 3 & $\begin{array}{l}\text { 1. Yolo } \\
\text { 2. Tona } \\
\text { 3. Ecaluil }\end{array}$ & $\begin{array}{l}\text { 1. Corazón } \\
\text { 2. Cabeza } \\
\text { 3. Cabeza }\end{array}$ & $\begin{array}{l}\text { 1. Centro del pensamiento y las } \\
\text { emociones } \\
\text { 2. Fuerza vital y centro de pensa- } \\
\text { miento } \\
\text { 3. Parte volátil del tona que se } \\
\text { encuentra débilmente atada al } \\
\text { cuerpo }\end{array}$ & Yolo & Duquesnoy 2001 \\
\hline $\begin{array}{l}\text { Náhuatl de } \\
\text { Zongolica }\end{array}$ & 4 & $\begin{array}{l}\text { 1. Yolo } \\
\text { 2. Tonalli } \\
\text { 3. Ecahuil } \\
\text { 4. Ihiyotl }\end{array}$ & $\begin{array}{l}\text { 1. Corazón } \\
\text { 2. Todoelcuerpo } \\
\text { 3. Alrededor del } \\
\text { cuerpo } \\
\text { 4.? }\end{array}$ & $\begin{array}{l}\text { 1. Entidad que se asocia a los esta- } \\
\text { dos deánimo } \\
\text { 2. Entidad que concentra la ener- } \\
\text { gia vital y resguarda la integridad } \\
\text { delsujeto } \\
\text { 3. Aura de naturaleza fría que } \\
\text { forma partedel tonalli } \\
\text { 4. Centro de las pasiones y senti- } \\
\text { mientos }\end{array}$ & Yolo & $\begin{array}{l}\text { Rodríguez López } \\
2000\end{array}$ \\
\hline Cuicateco & 3 & $\begin{array}{l}\text { 1. Sta vie en "cora- } \\
\text { zón" } \\
\text { 2. gua cu, deriva de } \\
\text { gua "transparente, } \\
\text { brillante, rubio" } \\
\text { 3. ndudu } \\
\text { "aliento" }\end{array}$ & & $\begin{array}{l}\text { Aunque no se le menciona explici- } \\
\text { tamente como un alma, es obvio } \\
\text { que se asignan funciones animicas } \\
\text { al soplo, pues la palabra ndu duno } \\
\text { sólo significa "aliento ", sino } \\
\text { tambićn "voz, habla, frase, } \\
\text { idioma, lengua, opinión [...]sabor, } \\
\text { olor " }\end{array}$ & & $\begin{array}{l}\text { Andersony } \\
\text { Concepción 1983, } \\
\text { pp. } 114,582,680\end{array}$ \\
\hline Chatino & 2 & $\begin{array}{l}\text { 1. Tyi'i« calor " } \\
\text { 2. Cuiti viento »o } \\
\text { " aliento " }\end{array}$ & $\begin{array}{l}\text { 1. Corazón } \\
\text { 2. Parte baja del } \\
\text { abdomen }\end{array}$ & $\begin{array}{l}\text { 1. Entidad que abandona el } \\
\text { cuerpodurante el sueño, centro de } \\
\text { las emociones y elemento calórico } \\
\text { cuyo exceso puedeser nocivo } \\
\text { 2. Entidad etérea, divisible y alta- } \\
\text { mentesensibleal mal viento }\end{array}$ & Tyíiolyumâ & $\begin{array}{l}\text { Pride y Pride 1970, } \\
\text { pp. 3, 11, 27, 87, 94, } \\
\text { 189, 271, 297; Barto- } \\
\text { lomé y Barabas } 1982\end{array}$ \\
\hline Mazatecos & 4 & $\begin{array}{l}\text { 1. Espiritu } \\
\text { 2. Sombra } \\
\text { 3. Hasen xahasen } \\
\text { "corazón" } \\
\text { 4. Xta «aliento" }\end{array}$ & & $\begin{array}{l}\text { 1. Lo que abandona el cuerpo } \\
\text { duranteelsueñoeselespiritu } \\
\text { 4. El aliento parece estar igual- } \\
\text { mente asociado a la voz, el sabor, } \\
\text { elorgulloyla arrogancia }\end{array}$ & & $\begin{array}{l}\text { Inchaustegui } 2000 \text {, } \\
\text { p. } 140 ; \\
\text { Jamieson Capen } \\
1996, \text { pp. } 73,173,188\end{array}$ \\
\hline Mixe & 2 & $\begin{array}{l}\text { 1. Ja'vin « corazón " } \\
\text { 2. Aanimi, del espa- } \\
\text { ñol «ánima } "\end{array}$ & & $\begin{array}{l}\text { 2. En composición con poh } \\
\text { "aire" designa al alma de los } \\
\text { muertos }\end{array}$ & & $\begin{array}{l}\text { Schoehals y Schoe- } \\
\text { hals 1965, p. } 188 \text {; } \\
\text { Hoogshagen y Hallo- } \\
\text { ren de Hoogshagen } \\
1993 \text {, p. } 262\end{array}$ \\
\hline Mixe & 3 & $\begin{array}{l}\text { 1. Hota'nimide } \\
\text { "ánima " } \\
\text { 2. Hibik oka noy', } \\
\text { amimi } \\
\text { 3. "Oy animi }\end{array}$ & $\begin{array}{l}\text { 1. El corazón, el } \\
\text { hígadoyelestómago } \\
2 \text { y } 3 \text { hombros }\end{array}$ & $\begin{array}{l}\text { 1. Sede del pensamiento. Entidad } \\
\text { en forma desolconalas } \\
\text { 2. Alma mala en forma de niño } \\
\text { conalas demurciélago } \\
\text { 3. Alma buena en forma de niño } \\
\text { conalas deáguila }\end{array}$ & Hota'nimi & Lipp 1991,pp. 43.46 \\
\hline Mixe & 1 & Hota'nimi & Todoelcuerpo & $\begin{array}{l}\text { Entre las siete o catorce almas o } \\
\text { partes de alma, la mitad son posi- } \\
\text { tivas y la mitad son negativas; la } \\
\text { mitad se mantienen en el cuerpo y } \\
\text { la mitad lo abandonan durante el } \\
\text { sueño }\end{array}$ & Hota'nimi & Lipp 1991, pp. 43-46 \\
\hline
\end{tabular}




\begin{tabular}{|c|c|c|c|c|c|c|}
\hline Huaves & 1 & Omeaats « corazón " & Elcorazón & $\begin{array}{l}\text { Centro de la vida, la memoria y las } \\
\text { emociones. Especie de viento que } \\
\text { abandona el cuerpo en el sueño y } \\
\text { elsusto. }\end{array}$ & Omeaals & $\begin{array}{l}\text { Garcia y Oseguera } \\
2001 \text {, pp. } 71-85\end{array}$ \\
\hline Triquis & 2 & $\begin{array}{l}\text { 1. Nimun « corazón " } \\
\text { 2. Güï «sol, dia»" }\end{array}$ & I. Elcorazón & $\begin{array}{l}\text { 1. Centro de la energía vital. Es lo } \\
\text { que secomparte con el nahualli }\end{array}$ & & $\begin{array}{l}\text { Garcia Alcaraz 1973, } \\
\text { p. } 233 \text {; Good 1979, } \\
\text { pp. } 58,69\end{array}$ \\
\hline Amuzgos & 1 & Nhoa & Elcorazón & $\begin{array}{l}\text { Centro de las funciones intelec- } \\
\text { tuales. Entidad que abandona el } \\
\text { cuerpodurante elsusto }\end{array}$ & & Garnung 2000 ,p. 31 \\
\hline Chinanteco & 2 & $\begin{array}{l}\text { 1. Jmï dzi " espiritu, } \\
\text { alma, vida, dar } \\
\text { vida ", dsi « aire" } \\
\text { 2. Juiñi } \\
\text { 3. mtyi, } \\
\text { "viento, aire, } \\
\text { aliento " } \\
\text { 4. fahjiih, " cora- } \\
\text { zón" }\end{array}$ & & $\begin{array}{l}\text { 1. Entidad divisible } \\
\text { 2. Esencia vital que tiene su sede } \\
\text { al mismo tiempo en el cuerpoy un } \\
\text { manantial. Entidad que se pierde } \\
\text { durante elsusto } \\
\text { Ignoramos si todos estos térmi- } \\
\text { nos se refieran a entidades distin- } \\
\text { tas o si, por el contrario, puedan } \\
\text { ser sinónimos }\end{array}$ & & $\begin{array}{l}\text { Bartolomé y Barabas } \\
\text { 1990, p. 192; Weitla- } \\
\text { ner y Castro 1973, } \\
\text { p. 171; Merrificld y } \\
\text { Anderson 1999; Rupp } \\
\text { y Rupp 1996, pp. 43, } \\
\text { 381; Skinner y Skin- } \\
\text { ner 2000, pp. 384, } \\
\text { 365; }\end{array}$ \\
\hline Mixteco & 4 & $\begin{array}{l}\text { 1. Anima yo } \\
\text { 2. Sombra } \\
\text { 3. Tono } \\
\text { 4. Tachi, " viento, } \\
\text { aire, alicnto " }\end{array}$ & 1. Corazón & $\begin{array}{l}\text { 1. Centro de los procesos intelec- } \\
\text { tuales } \\
\text { 2. Entidad que recubre al anima } \\
\text { yo y que se deambula por la tierra } \\
\text { como fantasma después de la } \\
\text { muerte } \\
\text { 3. Sustancia vital que anima al } \\
\text { individuo } \\
\text { 4. Término que probablemente } \\
\text { designe a los espíritus de los } \\
\text { muertos }\end{array}$ & Anima yo & $\begin{array}{l}\text { Flanet } 1977 \text {, pp. } 103- \\
\text { 105; Romney y Rom- } \\
\text { ney } 1973 \text {, p. } 74 \text {; Mak } \\
1959 \text {, p. } 127 \text {; Beaty de } \\
\text { Farris } 2002 \text {, p. } 78\end{array}$ \\
\hline Chontales & 2 & $\begin{array}{l}\text { 1. Wahma kitine } \\
\text { 2. pixam, "espiritu, } \\
\text { alma, sombra" }\end{array}$ & $\begin{array}{l}\text { En el corazón o el } \\
\text { aliento }\end{array}$ & $\begin{array}{l}\text { 1. Tiene forma humana y aban- } \\
\text { dona el cuerpo durante el sueno } \\
\text { 2. Entidad de la que dependen las } \\
\text { emociones y que se separa del } \\
\text { cuerpo durante el susto }\end{array}$ & Wahma kitine & Carrasco 1960 , p. 110 \\
\hline Zapoteco & 2 & $\begin{array}{l}\text { Dos clases principa- } \\
\text { les de almas } \\
\text { 1. Términos } \\
\text { referentes al corazón } \\
\text { aim, alm, laze, } \\
\text { yichilaźdao' } \\
\text { 2. Términos referen- } \\
\text { tes al aliento spirit, } \\
\text { sirijt, grasy'w; spiritw; } \\
\text { grasy' }\end{array}$ & & $\begin{array}{l}\text { 1. Centro de las emociones, la } \\
\text { memoria, el carácter, la maldad o } \\
\text { bondad, los deseos y ciertas cua- } \\
\text { lidades personales como la } \\
\text { humildad, la inventiva y la fiereza } \\
\text { 2. Se encuentra asociado a la } \\
\text { capacidad, el talento y el pensa- } \\
\text { miento. Se supone que es esta } \\
\text { entidad quien se separa del } \\
\text { cuerpo durante el susto, la ebrie- } \\
\text { dad y el desmayo } \\
\text { Parece existir cierta relación entre } \\
\text { la sombra y las almas de los muer- } \\
\text { tos, pues ambos elementos son } \\
\text { conocidos como bxin }\end{array}$ & & $\begin{array}{l}\text { Stubblefield y Miller } \\
\text { 1991, pp. 137, 154; } \\
\text { Long y Cruz 1999, } \\
\text { pp. 322, 351; Butler } \\
\text { 1997, pp. 266, 415 }\end{array}$ \\
\hline Popolocas & 1 & Sénni « corazón » & & $\begin{array}{l}\text { Es csta entidad quien se ocupa de } \\
\text { regular el pensamiento y las emo- } \\
\text { ciones. Y probablemente es tam- } \\
\text { bién esta misma alma quien se } \\
\text { separa durante el sueño o el susto }\end{array}$ & & $\begin{array}{l}\text { Austin y Kalstrom } \\
1995 ; \text { Jäcklein } 1974, \\
\text { p. } 264\end{array}$ \\
\hline Popolucas & 2 & $\begin{array}{l}\text { 1. Sin, “ cielo, fiesta } " \\
\text { 2. Jutucoto " cora- } \\
\text { zón " }\end{array}$ & & $\begin{array}{l}\text { 1. Es esta entidad quien se separa } \\
\text { del cuerpo durante el sueño y el } \\
\text { susto. Aunque no sabemos de la } \\
\text { creencia en entidades animicas } \\
\text { calóricas, resulta claro que el } \\
\text { susto implica la pérdida de calor; } \\
\text { pues, en un vocabulario moderno, } \\
\text { "curar espanto" es traducido } \\
\text { por supiu - piu "pepenar, reco- } \\
\text { ger", su "sol, dia" }\end{array}$ & & 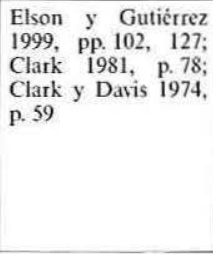 \\
\hline
\end{tabular}




\begin{tabular}{|c|c|c|c|c|c|c|}
\hline Zoque & 3 & $\begin{array}{l}\text { 1. Snima } \\
\text { 2. Sombra } \\
\text { 3. Jama " dia, sol " }\end{array}$ & & $\begin{array}{l}\text { 1. Entidad que se queda vagando } \\
\text { sobre la tierra después de la } \\
\text { muerte en caso de asesinato } \\
\text { 2. Elemento cuyas cualidades } \\
\text { determinan la posesión de pode- } \\
\text { res sobrenaturales } \\
\text { 3. Entidad que reside simultánea- } \\
\text { mente en el cuerpo y la montaña, } \\
\text { sirviendo al mismo tiempo de vín- } \\
\text { culo entre la persona y su nahualli }\end{array}$ & & $\begin{array}{l}\text { Lisbona Guillén } \\
\text { 1998, pp. 22-26; } \\
\text { Wonderly 1946, } \\
\text { p. } 98 \text {; Harrison, Har- } \\
\text { rison y Garcia 1981, } \\
\text { p. } 248\end{array}$ \\
\hline Teenek & 2 & $\begin{array}{l}\text { 1. Ejattal, de ejat } \\
\text { "vivir" } \\
\text { 2. Ch'ichiin relacio- } \\
\text { nado con ch'ichin } \\
\text { "ave" }\end{array}$ & $\begin{array}{l}\text { 1. Corazón } \\
\text { 2. Cabeza }\end{array}$ & $\begin{array}{l}\text { 1. Entidad invisible que, en forma } \\
\text { de angelito, da vitalidad a la per- } \\
\text { sona. Entre los huastecos de SLP } \\
\text { se dice que puede abandonar el } \\
\text { cuerpo durante el susto, entre los } \\
\text { de Veracruz no. El ejattal es tam- } \\
\text { bién la esencia vital de todo lo } \\
\text { viviente. Se pide al sol que cargue } \\
\text { al corazón del niño de ejattal; el } \\
\text { soles la fuente de energía motora. } \\
\text { 2. Entidad en forma de gota de } \\
\text { agua que, aunque se asocia al } \\
\text { vigor y al destino, es responsable } \\
\text { del pensamiento y la inteligen- } \\
\text { cia. Es lo que se separa durante el } \\
\text { sueño o el susto. }\end{array}$ & Ejattal (?) & $\begin{array}{l}\text { Ariel de Vidas } 2003 \text {, } \\
\text { pp. } 251-254 \text {; Alcorn } \\
1984 \text {, p. } 67\end{array}$ \\
\hline Mames & 1 & $\begin{array}{l}\text { Pixan "vivo o des- } \\
\text { pierto" }\end{array}$ & (?) & ¿Alma de los muertos? & Pixan & $\begin{array}{l}\text { Thompson } 1927 \text { - } \\
\text { 1932, p. } 67\end{array}$ \\
\hline Mames & 1 & $\begin{array}{l}\text { Nawal, de nahua } \\
\text { " coberlura, disfraz" }\end{array}$ & (?) & $\begin{array}{l}\text { Alma de los muertos. Entidad } \\
\text { asociada a la fecha de nacimiento } \\
\text { de la persona y, por consiguiente, } \\
\text { a su destino sobre la tierra }\end{array}$ & & $\begin{array}{l}\text { Tedlock 1982, } \\
\text { pp. } 110,124\end{array}$ \\
\hline $\begin{array}{l}\text { Maya yuca- } \\
\text { teco }\end{array}$ & 1 & $\begin{array}{l}\text { Pixan " vivo o des- } \\
\text { pierto" }\end{array}$ & (?) & (?) & (?) & $\begin{array}{l}\text { Villa Rojas } 1987 \text {, } \\
\text { p. } 431\end{array}$ \\
\hline $\begin{array}{l}\text { Maya yuca- } \\
\text { teco }\end{array}$ & 1 & Óol «corazón » & El corazón & $\begin{array}{l}\text { Centro de vitalidad, afección, } \\
\text { memoria, voluntad y emoción }\end{array}$ & (?) & $\begin{array}{l}\text { Güemes Pineda } 2000 \text {, } \\
\text { p. } 313\end{array}$ \\
\hline Chuj & 2 & $\begin{array}{l}\text { 1. Pixan " vivo, des- } \\
\text { pierto" } \\
\text { 2. An'ma de } \\
\text { "ánima " }\end{array}$ & (?) & (?) & (?) & La Farge 1947, p. 152 \\
\hline Chol & 2 & $\begin{array}{l}\text { 1. Ch'ujlel de chiuj } \\
\text { "divino, sagrado" } \\
\text { 2. Cuctal " torax" }\end{array}$ & 1. Todo el cuerpo & $\begin{array}{l}\text { 1. Especie de viento que aban- } \\
\text { dona el cuerpo durante el sueño } \\
\text { Aunque no se dice que sea un } \\
\text { alma, cabe notar que el corazón, } \\
\text { pusic'al, es considerado como el } \\
\text { centro de las emociones y el pen- } \\
\text { samiento }\end{array}$ & & $\begin{array}{l}\text { Whittaker y Warken- } \\
\text { tin } 1965 \text {, pp. } 88-89 \text {; } \\
\text { Aulie y Aulie } 1998 \text {, } \\
\text { pp. } 20,97,180,189\end{array}$ \\
\hline Mochó & 1 & $\begin{array}{l}\text { Cahcil } \\
\text { "sombra" }\end{array}$ & Corazón & $\begin{array}{l}\text { Centro de la memoria, entidad } \\
\text { que abandona el cuerpo durante } \\
\text { el sueño }\end{array}$ & Ćahcil & $\begin{array}{l}\text { García Ruiz 1987, } \\
\text { pp. } 276 \cdot 278\end{array}$ \\
\hline Tzotzil & 2 & $\begin{array}{l}\text { Ch'ulel de ch'uj } \\
\text { "divino, sagrado " } \\
\text { Ambas tienen el } \\
\text { mismo nombre }\end{array}$ & Todo el cuerpo & $\begin{array}{l}\text { Centro de la memoria, el pensa- } \\
\text { miento y las emociones. Se dice } \\
\text { que hay dos chiulel, uno muere y } \\
\text { el otro va al mundo de los muer- } \\
\text { tos }\end{array}$ & Chiulel & $\begin{array}{l}\text { Guiteras Holmes } \\
1961-1965\end{array}$ \\
\hline Tzotlil & 1 & $\begin{array}{l}\text { Ch'ulel de ch'uj } \\
\text { « divino, sagrado " }\end{array}$ & Corazón & $\begin{array}{l}\text { Centro de la memoria, el pensa- } \\
\text { miento y las emociones. }\end{array}$ & Chiulel & Köhler 1995 \\
\hline Tzeltal & 2 & $\begin{array}{l}\text { Chiulel de chiuj } \\
\text { "divino, sagrado " } \\
\text { Ambas tienen el } \\
\text { mismo nombre }\end{array}$ & Todo el cuerpo & & $\begin{array}{l}\text { Ch'ulel, una } \\
\text { de tales enti- } \\
\text { dades es } \\
\text { comida por el } \\
\text { nagual y la } \\
\text { otra va al } \\
\text { mundo de los } \\
\text { muertos }\end{array}$ & $\begin{array}{l}\text { Villa Rojas } 1990 \text {, } \\
\text { p. } 633\end{array}$ \\
\hline
\end{tabular}




\begin{tabular}{|c|c|c|c|c|c|c|}
\hline Tzeltal & $\left(\begin{array}{l}1 \\
(3)\end{array}\right.$ & $\begin{array}{l}\text { 1. Ch'ulel } \\
\text { 2. Ave del corazón } \\
\text { 3. Sombra }\end{array}$ & $\begin{array}{l}\text { 1. Corazón y cuerpo; } \\
\text { una montaña cer- } \\
\text { cana } \\
\text { 2. Corazón } \\
\text { 3. Corazón y cuerpo }\end{array}$ & $\begin{array}{l}\text { 1. Centro de las emociones, la } \\
\text { memoria y el pensamiento. Enti- } \\
\text { dad que se desprende durante el } \\
\text { sueño. } \\
\text { 2. Entidad asustadiza que aban- } \\
\text { dona el cuerpo en el susto } \\
\text { 3. Entidad etérea que fungecomo } \\
\text { reflejo del " verdadero " chiulel }\end{array}$ & Chiulel & $\begin{array}{l}\text { Pitarch 2000; Figue- } \\
\text { rola } 2000\end{array}$ \\
\hline Tzeltal & $\begin{array}{l}1 \\
(2)\end{array}$ & $\begin{array}{l}\text { 1. Chiulel } \\
\text { 2. K"al }\end{array}$ & $\begin{array}{l}\text { 1. Corazón y cuerpo } \\
\text { 2. Todo el cuerpo }\end{array}$ & $\begin{array}{l}\text { 1. Centro delas funciones intelec- } \\
\text { tuales } \\
\text { 2. Calor vital que anima al } \\
\text { cuerpo se asocia al status }\end{array}$ & Chiulel & Pitt-Rivers 1971; \\
\hline Tojolabal & 1 & $\begin{array}{l}\text { Altz'il « corazón, } \\
\text { estómago » }\end{array}$ & Corazón o estómago & $\begin{array}{l}\text { 1. Centro delas funciones intelec- } \\
\text { tuales. Se desprende durante el } \\
\text { susto o el sueño }\end{array}$ & Altz'il & $\begin{array}{l}\text { Ruz } 1983 \text {, pp. } 425- \\
431\end{array}$ \\
\hline Quiché & 2 & $\begin{array}{l}\text { 1. Jajalmac } \\
\text { 2. Chajenel }\end{array}$ & $\begin{array}{l}\text { 1. Parte frontal } \\
\text { 2. Parte dorsal }\end{array}$ & $\begin{array}{l}\text { 1. Entidad que abandona el } \\
\text { cuerpo durante el sueño } \\
\text { 2. Protege el cuerpo del dur- } \\
\text { miente }\end{array}$ & Jajalmac & McLean 1984, p. 399 \\
\hline Quiché & 1 & Anima & El corazón & $\begin{array}{l}\text { Centro de toda actividad intelec- } \\
\text { tual }\end{array}$ & $\begin{array}{l}\text { Tras la muerte } \\
\text { reencarna en } \\
\text { insecto }\end{array}$ & $\begin{array}{l}\text { Schultze Jena } 1947 \text {, } \\
\text { p. } 50\end{array}$ \\
\hline Kekchi & 1 & Šmuel, " su sombra " & & $\begin{array}{l}\text { Entidad antropomorfa y etérea } \\
\text { que se desprende del cuerpo } \\
\text { durante el sueño y el susto. Se } \\
\text { dice que tras la muerte esta alma } \\
\text { puede quedar vagando sobre la } \\
\text { tierra. }\end{array}$ & Šmuel & $\begin{array}{l}\text { Carson y Eachus } \\
\text { 1978, pp. } 49-52\end{array}$ \\
\hline Chortis & 2 & $\begin{array}{l}\text { 1. Pican " vivo", } \\
\text { "despierto " } \\
\text { 2. Mein }\end{array}$ & (?) & $\begin{array}{l}\text { 1. Se usa también con el sentido } \\
\text { de sombra. } \\
\text { 2. Se separa durante el sueño. }\end{array}$ & (?) & Wisdom 1961, p. 453 \\
\hline Tzutuhil & 2 & $\begin{array}{l}\text { 1. Ak'u'x, ak' } \\
\text { "negro ", u'x «cora- } \\
\text { zón ". "Espiritu o } \\
\text { santo " } \\
\text { 2. Awamima de } \\
\text { "ánima " }\end{array}$ & $\begin{array}{l}\text { 1. La sangre } \\
\text { 2. Corazón }\end{array}$ & $\begin{array}{l}\text { 1. Esencia vital del individuo } \\
\text { 2. Centro de las funciones intelec- } \\
\text { tuales }\end{array}$ & $\begin{array}{l}\text { Ananima } \\
\text { Ak'ux }\end{array}$ & $\begin{array}{l}\text { Mendelson } 1965 \text {, } \\
\text { pp. 115-116; Vallejo } \\
\text { Reyna 2001, pp. } 152- \\
153\end{array}$ \\
\hline Lencas & 1 & Angel o semejante & (?) & (?) & (?) & $\begin{array}{l}\text { Chapman 1985, } \\
\text { p. } 203\end{array}$ \\
\hline Bribri & 1 & $\begin{array}{l}\text { Sïwa " respiración, } \\
\text { aire, viento " }\end{array}$ & Rodillas, muñecas & & & Bozzoli 1979, p. 159 \\
\hline
\end{tabular}

TABLA 4 - Las almas-corazón

\begin{tabular}{|c|c|c|c|}
\hline Grupo étnico & Nombre de la entidad & Caracteristicas & Fuentes \\
\hline Mam & $\begin{array}{l}\text { Altzil " corazón o estó- } \\
\text { mago " }\end{array}$ & & Reynoso 1916 , pp. 51,88 \\
\hline Cakchiquel & Jux « corazón " & $\begin{array}{l}\text { El término " memoria », juxlab, está formado } \\
\text { por la misma raíz }\end{array}$ & $\begin{array}{l}\text { Guzmán } 1989 \text {, pp. } 61,62,63 \text {, } \\
96\end{array}$ \\
\hline $\begin{array}{l}\text { Maya } \\
\text { yucateco }\end{array}$ & Pixan u óol u corazón " & $\begin{array}{l}\text { Centro de la vitalidad, la afección, la memoria, } \\
\text { la voluntad y las emociones }\end{array}$ & $\begin{array}{l}\text { Ciudad Real 1995, p. } 2045 \text {; } \\
\text { Güemes Pineda } 2000 \text {, p. } 313\end{array}$ \\
\hline Chuj & Pixan " corazón" & $\begin{array}{l}\text { Esta es la entidad que se comparte con el } \\
\text { nahualli }\end{array}$ & La Farge 1947 , p. 152 \\
\hline Chontal & Pixan " corazón" & $\begin{array}{l}\text { De dicha entidad dependen las emociones, es lo } \\
\text { que se desprende del cuerpo durante el susto }\end{array}$ & Keller y Luciano 1997, p. 193 \\
\hline Tzeltal & $\begin{array}{l}\text { Chiulel "corazón y } \\
\text { chiulel son intercambia- } \\
\text { bles" }\end{array}$ & $\begin{array}{l}\text { Centro de las emociones, la memoria y el pensa- } \\
\text { miento. Entidad que se desprende durante el } \\
\text { sueño. }\end{array}$ & $\begin{array}{l}\text { Ara 1986, p. 26v; Pitarch } 2000 \text {; } \\
\text { Figuerola 2000; Villa Rojas } \\
\text { 1990, p. 633; Pitt-Rivers } 1971\end{array}$ \\
\hline
\end{tabular}




\begin{tabular}{|c|c|c|c|}
\hline Tzotzil & $\begin{array}{l}\text { Chiulel «corazón y } \\
\text { chiulel son intercambia- } \\
\text { bles } "\end{array}$ & $\begin{array}{l}\text { Centro de la memoria, el pensamiento y las } \\
\text { emociones. Se dice que hay dos chiulel, uno } \\
\text { muere y el otro va al mundo de los muertos }\end{array}$ & $\begin{array}{l}\text { Guiteras Holmes 1961-1965, } \\
\text { p. 304; Köhler } 1995\end{array}$ \\
\hline Chol & $\begin{array}{l}\text { Cuctal, " corazón o } \\
\text { tórax" }\end{array}$ & Es el centro de las emociones y el pensamiento & Aulie y Aulie 1998, p. 189, 20 \\
\hline Tzutuhil & $\begin{array}{l}\text { Ak'u'x, está formada } u ' x \\
\text { "la palabra para refe- } \\
\text { rirse al corazón de una } \\
\text { persona " }\end{array}$ & $\begin{array}{l}\text { Además de ser fuente de pensamiento, determi- } \\
\text { nada suerte de la persona; la vocación de los } \\
\text { especialistas rituales depende de ella. Por } \\
\text { último, sabemos que dicha entidad es la que } \\
\text { sobrevive a la muerte para ir a morar al infra- } \\
\text { mundo }\end{array}$ & Vallejo Reyna 2001, p. 152-153 \\
\hline Zapoteca & Lachi o la-e « corazón $"$ & $\begin{array}{l}\text { Es el centro de las emociones, la memoria, el } \\
\text { carácter, la maldad o bondad, los deseos y cier- } \\
\text { tas cualidades personales como la humildad, la } \\
\text { inventiva y la fiereza }\end{array}$ & $\begin{array}{l}\text { Córdoba 1987, fol. } 92 \text { r; Longy } \\
\text { Cruz 1999, p. } 243\end{array}$ \\
\hline Chatino & $\begin{array}{l}\text { Cresiya o tiye " cora- } \\
\text { zón " o " pecho, estó- } \\
\text { mago, corazón" }\end{array}$ & $\begin{array}{l}\text { Es el centro de las emociones. En su interior } \\
\text { radica el tyiti, elemento calórico que propor- } \\
\text { ciona al cuerpo la energia necesaria para la } \\
\text { vida. Es dicho elemento quien se separa del } \\
\text { cuerpo durante el sueno y el desmayo }\end{array}$ & Pride y Pride 1970 , p. 11 \\
\hline Chinanteco & $\begin{array}{l}\text { Fahjïh « corazón o } \\
\text { pecho " }\end{array}$ & & Rupp y Rupp 1996, p. 43 \\
\hline Cuicateco & Sta vie en, "corazón " & & $\begin{array}{l}\text { Anderson y Concepción } 1983 \text {, } \\
\text { p. } 114\end{array}$ \\
\hline Amuzgo & Nĩoa & $\begin{array}{l}\text { Centro de las funciones intelectuales. Entidad } \\
\text { que abandona el cuerpo durante el susto }\end{array}$ & Garnung 2000 , p. 31 \\
\hline Huave & Omeaats, "corazón» & $\begin{array}{l}\text { Entidad etérea responsable del pensamiento, la } \\
\text { memoria, los estados de ánimo y el comporta- } \\
\text { miento moral. Se supone que es el omeaats quien } \\
\text { abandona temporalmente el cuerpo durante el } \\
\text { sueño, el susto, el coito y la embriaguez, y quien } \\
\text { sobrevive a la destrucción del organismo tras la } \\
\text { muerte }\end{array}$ & $\begin{array}{l}\text { Stairs y Schafe de Stairs } 1981 \text {, } \\
\text { p. 152; Garcia y Oseguera } \\
\text { 2001, pp. 71-78 }\end{array}$ \\
\hline Mixe & $\begin{array}{l}\text { Javin, " corazón " o hot } \\
\text { a'nimi }\end{array}$ & $\begin{array}{l}\text { Bajo la forma de un sol con alas, se encarga } \\
\text { de regular el pensamiento. Algunos dicen que se } \\
\text { divide en } 3,7 \text { ó } 14 \text { partes que, difundido por } \\
\text { el cuerpo a través de la sangre, se concentra en el } \\
\text { corazón y los riñones. Se dice que, durante } \\
\text { el sueño, 2, } 3 \text { ó } 7 \text { de las almas, o partes de almas, } \\
\text { se desprenden del cuerpo para vagar libremente }\end{array}$ & $\begin{array}{l}\text { Schoehals y Schoehals } 1965 \text {, } \\
\text { pp. 164, 188; Lipp 1991, } \\
\text { pp. 43-46 }\end{array}$ \\
\hline Mixteco & $\begin{array}{l}\text { Añu, añima yo, "cora- } \\
\text { zón " }\end{array}$ & $\begin{array}{l}\text { Es una entidad inmortal que, habiendo residido } \\
\text { durante la vida en el corazón, abandona el } \\
\text { cuerpo tras la muerte para continuar su existen- } \\
\text { cia en el Más Allá. }\end{array}$ & $\begin{array}{l}\text { Dyk y Stoudt } 1973 \text {, p. } 1 \text {; } \\
\text { Pensinger } 1974 \text {, p. } 85\end{array}$ \\
\hline Popoloca & Ásénni, " corazón » & $\begin{array}{l}\text { Se ocupa de regular el pensamiento y las emo- } \\
\text { ciones. Se supone que dicha entidad es como un } \\
\text { aire que puede desprenderse del cuerpo durante } \\
\text { el susto o ser robada por las deidades de la tierra } \\
\text { y la lluvia }\end{array}$ & Austin y Kalstrom 1995 \\
\hline Popoluca & Jutucoto « corazón » & & Clark 1981, p. 78 \\
\hline Triqui & Nimum, " corazón » & $\begin{array}{l}\text { Es considerado como el centro de la energía } \\
\text { vital. Es lo que se comparte con el nahualli }\end{array}$ & $\begin{array}{l}\text { Good 1979; García Alcaraz; } \\
1973 \text {, p. } 233\end{array}$ \\
\hline Mazateco & $\begin{array}{l}\text { Hasen o xahasen, " cora- } \\
\text { zón" }\end{array}$ & $\begin{array}{l}\text { En un mito, se revive a una persona a partir de } \\
\text { una cabeza pero se afirma que " faltaba el cora- } \\
\text { zón " (Portal Arioso 1986, p. 56) }\end{array}$ & Jamieson Capen 1996, p. 188 \\
\hline Otomi & $\begin{array}{l}\text { Manmuay o mbüi, } \\
\text { "corazón ", " corazón o } \\
\text { estómago " }\end{array}$ & $\begin{array}{l}\text { El mbüi, " corazón o estómago " - derivado de } \\
\text { büi, " vivir, existir, habitar "-, es imaginado } \\
\text { como elcentro de las sensaciones, la afectividad, } \\
\text { la sexualidad y el conocimiento. En su interior } \\
\text { radican dos entidades diferentes, el nzahki y del } \\
\text { ntâhi }\end{array}$ & $\begin{array}{l}\text { Urbano } 1990, \text { fol. } 27 \mathrm{r} \text {; } \\
\text { Galinier 1979, p. 429; } 1990 \text {, } \\
\text { pp. 623-624, } 626\end{array}$ \\
\hline
\end{tabular}




\begin{tabular}{|c|c|c|c|}
\hline Totonaca & $\begin{array}{l}\text { äni'ma'j del español } \\
\text { "ánima» }\end{array}$ & $\begin{array}{l}\text { Existe la creencia en un alma, que puede sepa- } \\
\text { rarse del cuerpo durante el sueño o el susto. Lo } \\
\text { que va al inframundo después de la muerte es el } \\
\text { alma }\end{array}$ & $\begin{array}{l}\text { Aschman 1973, pp. 3, 14; } \\
\text { Córdova Olivares } 1990, \\
\text { pp. } 25-26\end{array}$ \\
\hline Matlatzinca & $\begin{array}{l}\text { Imbotuyaa, «corazón o } \\
\text { estómago » }\end{array}$ & & Basalenque 1975 , pp. 23,79 \\
\hline Huichol & Iyari, " corazón " & $\begin{array}{l}\text { El corazón es el centro de la vitalidad mental, de } \\
\text { la memoria, de las emociones, de la voluntad y } \\
\text { del conocimiento. Es la entidad que se va al } \\
\text { mundo de los antepasados después de la muerte }\end{array}$ & $\begin{array}{l}\text { Casillas Romo } 1990 \text {, p. } 70 ; \\
\text { Weigand y Garcia } 1992 \text {, p. } 220\end{array}$ \\
\hline Purépecha & Mintzita, «corazón» & $\begin{array}{l}\text { Se dice que, tras la muerte, si la persona cumplió } \\
\text { su misión, su alma transita libremente hasta " la } \\
\text { gloria ". Si el individuo " no cumplió ", el alma } \\
\text { se extravia en este camino o su acceso a " la } \\
\text { gloria " es interferido por seres sobre-naturales. } \\
\text { Es algo que se separa durante el sueño o el susto. } \\
\text { De ella dependen el vigor, la felicidad, el valor y } \\
\text { la salud }\end{array}$ & Gallardo Ruiz 2005, pp. $83-90$ \\
\hline Teenek & Ejattal, de ejat " vivir " & $\begin{array}{l}\text { Da vitalidad a la persona a quien se encuentra } \\
\text { asociado. Aunque se le supone invisible, se ima- } \\
\text { gina que tiene forma de angelito. En SL.P se dice } \\
\text { que puede separarse del cuerpo durante el susto, } \\
\text { en Veracruz no }\end{array}$ & $\begin{array}{l}\text { Ariel de Vidas } 2003, \text { pp. } 251- \\
254 \text {; Alcorn } 1984 \text {, p. } 67\end{array}$ \\
\hline Tojolabal & $\begin{array}{l}\text { Altzil "corazón o estó- } \\
\text { mago " }\end{array}$ & $\begin{array}{l}\text { Aparentemente es de dicha entidad que derivan } \\
\text { el sentimiento, el carácter y el pensamiento. } \\
\text { Como en otros casos, se considera que, además } \\
\text { de compartirse esta alma con el nahual, existe la } \\
\text { posibilidad de que ésta se separe del cuerpo } \\
\text { durante el suenoo o el susto }\end{array}$ & Ruz 1983, pp. $425-431$ \\
\hline Quiché & Anima & $\begin{array}{l}\text { Centro de toda actividad intelectual que, tras la } \\
\text { muerte, reencarna en insecto }\end{array}$ & Schulize Jena 1947, p. 50 \\
\hline
\end{tabular}

Tabla 5 - Las almas-aliento

\begin{tabular}{|c|c|c|c|c|}
\hline Grupo étnico & Término & Caracteristicas & Ubicación & Fuente \\
\hline Bribri & $\begin{array}{l}\text { Siwa " respiración, aire, } \\
\text { viento " }\end{array}$ & $\begin{array}{l}\text { Es insertada en el feto bajo la } \\
\text { forma de una pequeña figurilla } \\
\text { semejantealas realizadasen barro }\end{array}$ & $\begin{array}{l}\text { Articulaciones, } \\
\text { principalmente, } \\
\text { rodillas y muñecas }\end{array}$ & $\begin{array}{l}\text { Bozzoli 1979, pp. } 152 \text {, } \\
159\end{array}$ \\
\hline Cuicateco & Ndu du " aliento" & $\begin{array}{l}\text { Aparentemente se encuentra aso- } \\
\text { ciado a la voz, el habla, la opi- } \\
\text { nión, el sabor y el olor }\end{array}$ & & $\begin{array}{l}\text { Anderson y Concep- } \\
\text { ción 1983, pp. } 114,582\end{array}$ \\
\hline Chatino & $\begin{array}{l}\text { Cati cui'i; " siete vien- } \\
\text { tos" }\end{array}$ & $\begin{array}{l}\text { Son estos quienes, tras un sobre- } \\
\text { salto, pueden separarse del } \\
\text { cuerpo y ser robados por las dei- } \\
\text { dades de la tierra y la lluvia }\end{array}$ & $\begin{array}{l}\text { Parte baja del } \\
\text { abdomen }\end{array}$ & $\begin{array}{l}\text { Bartolomé y Barabas } \\
1982 \text {, pp. 123-124, } 132 \text {. } \\
135\end{array}$ \\
\hline Chinanteco & $\begin{array}{l}\text { M tyi, "viento, aire, } \\
\text { aliento " jmi } d s i \\
\text { " espiritu, alma, vida, } \\
\text { dar vida ", dsi " aire " }\end{array}$ & & & $\begin{array}{l}\text { Skinner y Skinner } 2000 \text {, } \\
\text { pp. } 384,365 ; \text { Merrifield } \\
\text { y Anderson 1999; Rupp } \\
\text { y Rupp 1996, pp. } 43 \text {, } \\
381\end{array}$ \\
\hline Mazateco & Xta " aliento" & $\begin{array}{l}\text { Se encuentra asociado a la voz, el } \\
\text { sabor, el orgullo y la arrogancia }\end{array}$ & & $\begin{array}{l}\text { Jamieson Capen } 1996 \text {, } \\
\text { pp. } 73,173,188\end{array}$ \\
\hline Mixe & Poj", "aire" & $\begin{array}{l}\text { Alma de los muertos que vaga por } \\
\text { la tierra y se encuentra ligada al } \\
\text { lugar de muerte o sepultura }\end{array}$ & & $\begin{array}{l}\text { Hoogshagen y Halloren } \\
\text { de Hoogshagen 1993, } \\
\text { p. 262; Lipp 1991, p. } 43\end{array}$ \\
\hline Mixteco & Tachi « viento " & $\begin{array}{l}\text { Aunque de las almas-aliento mix- } \\
\text { tecas conocemos todavia muy } \\
\text { poco, sabemos que éstas pueden } \\
\text { emanarse como gases patógenos } \\
\text { de los cuerpos putrefactos }\end{array}$ & & $\begin{array}{l}\text { Beaty de Farris } 2002 \text {, } \\
\text { p. } 78 \text {; Mak 1959, p. 127; } \\
\text { Romney y Romney } \\
1973 \text {, p. } 74\end{array}$ \\
\hline
\end{tabular}




\begin{tabular}{|c|c|c|c|c|}
\hline Zapoteco & $\begin{array}{l}\text { Pée, penepaa " aliento ", } \\
\text { grasyw; spiritw " aliento" }\end{array}$ & $\begin{array}{l}\text { En la Colonia temprana, se des- } \\
\text { cribia al aliento como « lo que da } \\
\text { vida a lo que vive y le da virtud } \\
\text { motiva y ser ". El aliento, en la } \\
\text { actualidad, se encuentra asociado } \\
\text { a la capacidad, el talento y el pen- } \\
\text { samiento. Se supone que es esta } \\
\text { entidad quien se separa del } \\
\text { cuerpo durante el susto, la ebrie- } \\
\text { dad y el desmayo }\end{array}$ & & $\begin{array}{l}\text { Córdoba 1987, fol. 22r- } \\
22 v ; \text { Stubblefield y } \\
\text { Miller 1991, pp. 137, } \\
\text { 154; Long y Cruz 1999, } \\
\text { pp. 322, 351; Butler } \\
\text { 1997, pp. 266, 415 }\end{array}$ \\
\hline Pocomchi & Uxlab " aliento " & & & $\begin{array}{l}\text { Morán y Zúñiga 1991, } \\
\text { p. } 258\end{array}$ \\
\hline Matlatzinca & Nituhami, " aliento" & $\begin{array}{l}\text { Comparte su raíz con chijabi } \\
\text { "sangre" }\end{array}$ & & $\begin{array}{l}\text { Basalenque 1975, } \\
\text { pp. 23, 79, 138; Esca- } \\
\text { lante Hernández 1997, } \\
\text { pp. 24, 38; Reynoso } \\
\text { González 1998, p. } 82\end{array}$ \\
\hline Otomí & $\begin{array}{l}\text { Nate. nóhia, na ihiphi } \\
\text { " aliento "; } \\
\text { "aliento " }\end{array}$ & $\begin{array}{l}\text { Se trata de una entidad que, } \\
\text { además de identificarse con la } \\
\text { sombra, es aquello que se com- } \\
\text { parte con el nahualli y quien se } \\
\text { desprende del cuerpo tras el } \\
\text { sueñoy el susto. Tras la muerte, es } \\
\text { ella quien viaja al inframundo }\end{array}$ & $\begin{array}{l}\text { Corazón o estó- } \\
\text { mago }\end{array}$ & $\begin{array}{l}\text { Urbano } 1990 \text {, fol. } 27 \mathrm{r} \text { - } \\
28 \text { r; Galinier } 1990 \text {, } \\
\text { pp. } 618-619,622-624 \text {, } \\
626 ; 1979 \text {, p. } 429\end{array}$ \\
\hline Purépecha & $\begin{array}{l}\text { Hiretaqua "aliento, } \\
\text { huelgo, resuello " }\end{array}$ & & & $\begin{array}{l}\text { Velásquez } \quad \text { Gallardo } \\
\text { 1978, p. 164; Gilberti } \\
\begin{array}{ll}\text { 1989-1997, } & \text { pp. } 254, \\
257 . & \end{array}\end{array}$ \\
\hline $\begin{array}{l}\text { Maya yuca- } \\
\text { teco }\end{array}$ & $I k^{\prime}$ " viento " & Está asociado a la vitalidad & & $\begin{array}{l}\text { Diccionario maya Cor- } \\
\text { demex } 1980 \text {, p. } 21 \text {; Ciu- } \\
\text { dad Real } 1995, \text { p. } 2045\end{array}$ \\
\hline Rarámuri & $\begin{array}{l}\text { Wwigála, de iwi «respi- } \\
\text { rar» }\end{array}$ & $\begin{array}{l}\text { Las emociones, el pensamiento y } \\
\text { la respiración dependen de dicha } \\
\text { entidad. Es esta entidad quien se } \\
\text { separa del cuerpo durante el } \\
\text { sueño, el susto o la muerte }\end{array}$ & $\begin{array}{l}\text { El corazón y el } \\
\text { resto del cuerpo }\end{array}$ & $\begin{array}{l}\text { Bennett y Zingg 1935, } \\
\text { pp. 238, 259, 323-324; } \\
\text { Merril 1992 }\end{array}$ \\
\hline
\end{tabular}

TABLA 6 - Las almas-sombra

\begin{tabular}{|l|l|l|l|l|}
\hline Grupo étnico & Término & Características & Ubicación & Fuente \\
\hline Mixteco & Sombra & $\begin{array}{l}\text { Es un elemento que, tras el } \\
\text { deceso, es absorbido por el lugar } \\
\text { de su muerte o, si se hacen los } \\
\text { ritos adecuados, de su entierro. } \\
\text { Cuando se trata de muertes vio- } \\
\text { lentas, es dicha entidad quien se } \\
\text { pasea por la tierra asustando a las } \\
\text { personas }\end{array}$ & $\begin{array}{l}\text { Flanet } \\
117\end{array}$ \\
\hline Totonaca & Sombra & $\begin{array}{l}\text { Se trata de una entidad que, según } \\
\text { la fuerza y las cualidades perso- } \\
\text { nales, cs irradiada por la persona } \\
\text { bajo la forma de mal de ojo. EI } \\
\text { mal aire es provocado por la } \\
\text { introducción de un aire o sombra } \\
\text { ajeno a la persona; entre otras } \\
\text { cosas esto sucede a consecuencia } \\
\text { de las relaciones sexuales ilicitaso } \\
\text { el contacto con un cadáver }\end{array}$ & $\begin{array}{l}\text { Córdosa Olivares 1990, } \\
\text { pp. 25-26; } \\
\text { Espinosa 1998, p. 208. } \\
\text { Gutiérrez }\end{array}$ \\
\hline
\end{tabular}




\begin{tabular}{|c|c|c|c|c|}
\hline Kekchí & $\begin{array}{l}\text { Simuel, de muh "som- } \\
\text { bra } "\end{array}$ & $\begin{array}{l}\text { Se trata de una cntidad antropo- } \\
\text { morfa y etérea que se separa del } \\
\text { cuerpo durante el sueño y el } \\
\text { susto, provocando en el segundo } \\
\text { caso graves enfermedades que, de } \\
\text { no remediarse, producirian la } \\
\text { muerte. En algunas ocasiones, } \\
\text { esta entidad regresa al mundo } \\
\text { para molestar o ayudar a sus } \\
\text { semejantes. Si la persona muriera } \\
\text { asesinada o "antes de tiempo ", } \\
\text { el šmuel estaria condenado a } \\
\text { vagar por la tierra como una som- } \\
\text { bra hasta que llegara el momento } \\
\text { en que debia morir }\end{array}$ & & $\begin{array}{l}\text { Carson y Eachus 1978, } \\
\text { pp. } 45-49\end{array}$ \\
\hline Zapoteco & Bxin "sombra " & $\begin{array}{l}\text { Parece existir cierta relación entre } \\
\text { la sombra y las almas de los muer- } \\
\text { tos, pues ambos elementos son } \\
\text { conocidos como bxin }\end{array}$ & & $\begin{array}{l}\text { Long y Cruz 1999, } \\
\text { pp. } 21,352\end{array}$ \\
\hline Purépecha & Zuanda « sombra " & $\begin{array}{l}\text { Cuando el individuo es alcanzado } \\
\text { por la muerte la sombra se disipa, } \\
\text { se pierde o vaga en el mundo de } \\
\text { los vivos asustándolos. Puede } \\
\text { desprenderse en cualquier mo- } \\
\text { mento y su pérdida se interpreta } \\
\text { como la introyección de un aire } \\
\text { que ha desplazado a la sombra }\end{array}$ & En la cabeza & $\begin{array}{l}\text { Gallardo Ruiz 2005, } \\
\text { pp. } 83-90\end{array}$ \\
\hline Mochó & Cahcil, "sombra" & $\begin{array}{l}\text { Esta alma, a la que también se } \\
\text { asocia la memoria, es capaz tanto } \\
\text { de separarse del cuerpo durante el } \\
\text { sueño y el susto como de viajar al } \\
\text { inframundo tras la muerte }\end{array}$ & El corazón & $\begin{array}{l}\text { García Ruiz } 1987 \text {, } \\
\text { pp. } 276-278,282\end{array}$ \\
\hline Tzeltal & Nojk'etal, " sombra " & $\begin{array}{l}\text { La sombra, a quien se imagina } \\
\text { como una entidad etérea y antro- } \\
\text { pomorfa que se queda vagando } \\
\text { sobre la superficie terrestre tras la } \\
\text { muerte de la persona }\end{array}$ & El corazón & Figuerola 2005 \\
\hline Zoque & Sombra & $\begin{array}{l}\text { Según sus cualidades, determina } \\
\text { la posesión de poderes sobre- } \\
\text { naturales }\end{array}$ & & $\begin{array}{l}\text { Harrison, Harrison y } \\
\text { Garcia 1981, p. } 248 \text {; } \\
\text { Lisbona Guillen 1998, } \\
\text { pp. } 22,26\end{array}$ \\
\hline
\end{tabular}


TABLA 7 - Las almas calóricas

\begin{tabular}{|c|c|c|c|c|}
\hline Grupo étnico & Término & Características & Ubicación & Fuente \\
\hline Chatino & $T y i i$ & $\begin{array}{l}\text { Elemento calórico que propor- } \\
\text { ciona al cuerpo la energia necesa- } \\
\text { ria para la vida. Se desprende del } \\
\text { cuerpo durante el sueño, mas no } \\
\text { durante el susto. Se supone que el } \\
\text { exceso de calor puede ser perjudi- } \\
\text { cial para los demás }\end{array}$ & En el corazón & $\begin{array}{l}\text { Bartolomé y Barabas } \\
\text { 1982, pp. 123-124, 132- } \\
135\end{array}$ \\
\hline Mixteco & Ini « calor " & $\begin{array}{l}\text { Se traduce como " espíritu lo que } \\
\text { da vida ". Aun si el término ini no } \\
\text { parece seguir en uso, sabemos } \\
\text { que, para los mixtecos contem- } \\
\text { poráneos, la sangre se encarga de } \\
\text { difundir por el cuerpo una suerte } \\
\text { de calor que da vigor y fuerza a la } \\
\text { persona }\end{array}$ & & $\begin{array}{l}\text { Alvarado 1962, fol. 17r, } \\
\text { 21v, 104v; Flanet 1977, } \\
\text { p. } 103\end{array}$ \\
\hline Triqui & $\begin{array}{l}\text { Güi « sol, dia; gente, per- } \\
\text { sona, alma » }\end{array}$ & & & Good 1979 , p. 58 \\
\hline Tzotzil & C'al " calor" & $\begin{array}{l}\text { Elemento calórico, asociado al } \\
\text { ch'ulel, que se distribuye por el } \\
\text { cuerpo aportándole la fuerza } \\
\text { necesaria para la vida. Todo el } \\
\text { cuerpo contiene este elemento y } \\
\text { conforme se avanza en la vida este } \\
\text { tiende a aumentar. El calor puede } \\
\text { ser usado para dañar a los demás }\end{array}$ & Todo el cuerpo & $\begin{array}{l}\text { Guiteras Holmes 1961- } \\
\text { 1965, pp. I11, 140, 150, } \\
\text { 296; Laughlin y Kara- } \\
\text { sik 1988, pp. 22, 91-93; } \\
\text { Köhler 1995, p. 22; } \\
\text { Vogt 1969, pp. 369-371; } \\
\text { Page Pliego 2002, } \\
\text { pp. 171, 175, 177, 178- } \\
\text { 179, 181-184, 220, 256 }\end{array}$ \\
\hline Tzeltal & $C^{\prime} a l$ " calor" & $\begin{array}{l}\text { Da salud, vitalidad y poder poli- } \\
\text { tico económico y sexual a quienes } \\
\text { lo poseen en mayor cantidad. }\end{array}$ & Todo el cuerpo & 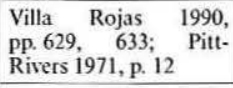 \\
\hline Teenek & Ch'ichiin & $\begin{array}{l}\text { El ch'ichïin, asociado a un pájaro, } \\
\text { es un elemento caliente con forma } \\
\text { degota de agua que se encarga del } \\
\text { pensamiento y la inteligencia de } \\
\text { la persona. Cuando una persona } \\
\text { nace con dos remolinos en la } \\
\text { cabeza, también Ilamados } \\
\text { ch'ichiïn, se supone que tendrá } \\
\text { más vigor, valor y, por consi- } \\
\text { guiente estará predestinado a } \\
\text { convertirse en especialista ritual. } \\
\text { Como en otros casos, se supone } \\
\text { que el ch'ichiïn es un componente } \\
\text { fragmentario de suerte que, en } \\
\text { cada susto se puede perder una } \\
\text { parte de él }\end{array}$ & La cabeza & $\begin{array}{l}\text { Ariel de Vidas 2003, } \\
\text { pp. 251-254; Alcorn } \\
\text { 1984, p. } 67\end{array}$ \\
\hline
\end{tabular}




\section{NOTAS}

Este trabajo fue realizado con el apoyo del Programa de Becas Posdoctorales de la UNAM. Agradezco igualmente a mi maestro Alfredo López Austin, cuyo apoyo y enseñanzas han sido fundamentales para la realización de la presente investigación. Doy las gracias también a la Dra. Yolanda Lastra por su ayuda en el análisis etimológico de términos otomíes y al Dr. Ramón Arzápalo por su análisis de vocablos mayas.

1. Entiéndase por el término «alma » cualquier elemento, pensado como indispensable para la vida, que, teniendo generalmente una consistencia diferente de la del cuerpo pesado, participa en los procesos psico-sociales que dan plena existencia al individuo dentro de una cultura determinada. Con idéntico sentido, usaremos el binomio " entidades anímicas ».

2. A primera vista, comparación con grupos no mesoamericanos pudiera parecer rara. No obstante, cabe aclarar que la mesoamericanidad de un grupo no es un dato objetivo, pues los límites de esta región cultural suelen variar en función de los autores que la definan. Ferrero (2000), por ejemplo, considera a los lencas y los jicaques como mesoamericanos mientras que Kirchhoff (1943) no. Hers (1989), Braniff (1995) y Dávila Cabrero (2000) son sólo algunos de los autores que han notado la existencia de semejanzas culturales entre las sociedades del interior y el exterior de Mesoamérica.

3. Entre los primeros figuran los rarámuris, los borucas, los lencas, los bribris, los cabecares y los tolupan-jicaques. Entre los segundos, se cuenta a los coeur d'alène, los ojibwa, los quechuas, los cahuilla, los shoshone, los paiute, los ute, los tubatulabal, los navahos, los apaches, los yauyos, los aymaras, los inuit, los atsine, los cherokee, los hidatsa, los pomo, los navajos, los eyak, los kwakiutl, los nootka, los hurón, los coyukan, los carrier, los atapascanos del oeste, los tlingit, los algonquinos, los cheyennes, los choctaw, los catawa, los dakota, los yumas, los maricopa, los huvasupai, los mohave, los jivaros y los campa. Es gracias al bastísimo trabajo de compilación de Hultkrantz (1953) que disponemos de mucha mayor información sobre los indios del norte que sobre los del sur del continente.

4. Para los mixes, el alma del corazón no es exactamente un ave sino que tiene la forma de « sol pero con alas como de pájaro » (Lipp 1991, p. 43). En la Sierra Negra se afirma tanto que toamima tiene forma de zopilote o mariposa, según el género, como que es como la persona misma, " sólo que es puro espiritu » (Romero López 2003, p. 87). Según lo que menciona Ariel de Vidas (2003, p. 252), los teenek consideran que el alma del corazón se asocia a un angelito mientras que es el alma de la cabeza quien tiene forma de ave.

5. El hecho de que los totonacas de la Sierra imaginen al « alma » como un diminuto personaje parece más bien estar ligado a la influencia europea; pues, además de que tales representaciones no son comunes en Mesoamérica, las imagenes de este tipo eran frecuentes en el Occidente Medieval (ver Ichon 1973, p. 205; Baschet 2000).

6. « El papa le cortaba el pecho y le sacaba el corazón y lo alzaba con la mano todo lo que podía extender el brazo a lo alto y daba el vaho al sol » (Durán 1967, II, p. 54).

7. Aunque pudiera pensarse que se trata de una transformación, cabe remarcar que, en este párrafo, el término empleado no es cuepa « tornar » sino ixiptlatia « representar ».

8. Es interesante notar que, para los zoques, es el alma-calórica quien existe simultáneamente en el cuerpo y la montaña (Lisbona Guillén 1998, pp. 22-26).

9. Lipp (1991, pp. 43-44) explica que dicha entidad « se localiza en el corazón, pero el término hot comprende tanto al corazón como al estómago y el hígado, ni: hot »).

10. Entre los quechuas, por ejemplo, el alma-corazón (sonqo), en compañia de los riñones (rurun), controla las emociones; a él se asocian los pensamientos, las intenciones, la conciencia, el juicio, la voluntad, el entendimiento y el intelecto. Además, el corazón es lo que da su carácter específico al ser humano, es lo que lo distingue de los animales. De modo semejante a lo que se observa en Mesoamérica, la pérdida del sonqo implica la enfermedad, la muerte y la falta de la fertilidad. Se cree que los humanos corren el riesgo de que sus corazones sean comidos por los espíritus de las montañas (Greenway 1987, pp. 266, 269-272, 280). 
11. Según Hultkrantz (1953, pp. 179-180), dicha entidad es igualmente dificil de identificar entre los pueblos indigenas norteamericanos. De acuerdo con este autor (ibid., p. 181), una caracteristica de dicha entidad es que ella no suele ser idéntica a ningún órgano.

12. Entre los zapotecos resulta claro que lo que se pierde es de naturaleza fría. Don Juvenal, el informante de Weisz (1996, p. 78) explica que el susto es una enfermedad caliente « porque se va secando el hombre [...]. Con el sol no se puede hacer tratamiento alguno, porque las radiaciones también pueden llegar a quemar ». De hecho, parece ser que en un mismo grupo se puede perder tanto lo frío como lo caliente « El espiritu queda tirado donde se espantó. La tierra absorbe los ácidos y causa frío o calor y agotamiento " (ibid.).

13. "Tras la muerte, la última de las almas corporales muere, y el espíritu del individuo o "viento de la muerte", $o$ 'kipoh, llega. El espiritu del muerto habita en la sepultura del cuerpo, donde una "casa" ha sido construida para él » (Lipp 1991, p. 45).

14. Ello nos conduce a plantearnos el problema de si existe una relación entre el ihiyotl y aquellos seres telúricos, emparentados con los antiguos tlaloque, que en la literatura etnográfica aparecen seguido con el nombre de aires. Pues, aunque muchas veces los aires son considerados como seres humanos que murieron bajo la influencia de deidades acuáticas, no resulta claro de qué parte del ser humano resulta su existencia; ya que, como hemos visto, tanto el yolia como el ihiyotl suelen ser pensados como aires (para mayor información sobre tales seres, véanse los trabajos de Montoya Briones 1964, pp. 158-159, 181; Signorini y Lupo 1989, pp. 138-145; Álvarez Heydenreich 1987, pp. 120-130; Redfield 1930, pp. 163-165; Sandstrom 1991, pp. 252-253).

15. Entre los cuicatecos, existen dos formas anímicas distintas: el sta vie en « corazón » y el gua cu, de gua "transparente, brillante, rubio " pero, por desgracia, carecemos de cualquier otro dato al respecto (Anderson y Concepción 1983, pp. 114, 582). Es probable que el soplo sea igualmente considerado como una entidad anímica, pues la palabra $n d u d u$ no sólo significa " aliento », sino también « voz, habla, frase, idioma, lengua, opinión [...] sabor, olor » (ibid, p. 680).

16. En primer lugar, tenemos al ámima, un elemento que supuestamente se quedaría vagando sobre la tierra si la persona correspondiente fuera asesinada (Harrison, Harrison y García 1981, p. 248). En segundo, aparece algo conocido como sombra, que, según sus cualidades, determina la posesión de poderes sobrenaturales. Por último, encontramos al jama « sol », una entidad que sirve de vínculo con el nahualli (Lisbona Guillén 1998, pp. 22, 26).

17. Entre los chinantecos encontramos cuatro diferentes términos empleados para traducir del castellano « alma », " ánima », " cspíritu »: m tyi, « viento, aire, aliento » (Skinner y Skinner 2000, pp. 384, 365), fahjiihh, « corazón » (Rupp y Rupp 1996, p. 43), jmi dsi « espíritu, alma, vida, dar vida », dsi « aire » (Merrifield y Anderson 1999; Rupp y Rupp 1996, p. 381) y juiñi (Bartolomé y Barabas 1990, p. 203). El problema es que, hasta ahora, seguimos sin saber si estos términos son sinónimos o si, por el contrario, aluden a entidades diferentes.

18. Entre los mochó se cree en una entidad llamada sombra pero se supone que esta vive en el corazón (García Ruiz 1987, pp. 276-278, 282).

19. Al respecto, observamos que además de tonacayo « nuestra carne », los mexicas nombraban al cuerpo in tlalli in zoquitl « la tierra y el barro " y Chicomoztoc " lugar de las siete cavernas». Los mixtecos contemporáneos le llaman coño ñuhu yu, un término formado por la aglutinación de los vocablos « carne ", " tierra " y « nosotros »; los amuzgos le llaman si'tzo" « carne-tierra », en mixe se le denomina ñune' yu: ñumu « tierra », ne' $y u$ « lodo » y los tzeltales lo nombran yach'alel « lodo ». Ello sin mencionar que los lacandones y los tzotziles de Chenalhó dicen explicitamente que el hombre esta hecho de tierra (López Austin 1996, pp. 172-173; Flanet 1982, p. 159; Garnung 2000, p. 33; Monaghan 1995, p. 203; Figuerola 2005; Cline 1944, pp. 108-110; Guiteras Holmes 1965, p. 255).

20. El vocabulario de Guzmán (1989) no traduce jux por « alma », « ánima » o " espíritu »; mas el hecho de que la palabra memoria, juxlab, aparezca compuesta por esta misma raiz nos hace pensar que, cuando menos, algunas funciones intelectuales estaban asociadas al corazón.

21. El número de entidades por grupo representa la cantidad total de almas registradas; mas ello no necesariamente significa que todas ellas se encuentren simultáneamente en una misma comunidad. 
ABELL Robert L.

\section{BIBLIOGRAFÍA}

1970 Los popolocas orientales: un estudio etnológico sobre San Juan Atzingo, tesis de licenciatura, UDLA, Puebla.

Adams Richard

1952 Un análisis de las creencias y prácticas médicas de un pueblo indígena de Guatemala (con sugerencias relacionadas con la práctica de medicina en el área maya), Editorial del Ministerio de Educación Pública, Guatemala.

ALCorn Janis

1984 Huastec Mayan ethnobotany, University of Texas Press, Austin.

Alvarado Francisco

1962 Vocabulario en lengua mixteca, Wigberto Jiménez Moreno (ed.), con un apéndice que contiene un glosario extraído de « Arte en lengua mixteca » de Fr. Antonio de los Reyes, INI/INAH/SEP, México.

Álvarez Heydenreich Laurencia

1987 La enfermedad y la cosmovisión en Hueyapan, Morelos, INI, México.

ANDERSON Richard y Roque Hilario CONCEPCIÓN

1983 Diccionario cuicateco, Instituto lingüístico de Verano, Vocabularios indígenas $n^{\circ} 6$, México.

ARA fray Domingo de

1986 Vocabulario en lengua tzeldal según el orden de Copanabastla, Mario Humberto Ruz (ed.), IIF/CEM/UNAM, México.

Aramoni Abbat María Elena

1990 Tlalocan tata, Tlalocan nana. Hierofanías y testimonios de un mundo indigena, INAH, México.

Ariel de Vidas Anath

2003 El trueno ya no vive aquí. Representación de la marginalidad y construcción de la identidad teenek (Huasteca veracruzana, México), CIESAS/CEMCA/El Colegio de San Luis/IRD, México.

Aschman Herman

1973 Vocabulario totonaco de la Sierra, Instituto lingüístico de Verano, Vocabularios indigenas $\mathrm{n}^{\circ} 7$, México.

Aulie Wilbur y Evelyn Aulie

1998 Diccionario ch'ol de Tumbalá, Chiapas, Instituto lingüístico de Verano, Vocabularios indígenas $n^{\circ} 121$, México.

Austin Jeanne y Marjorie Kalstrom

1995 Diccionario popoloca de San Juan Atzingo, Puebla, Instituto lingüístico de Verano, Vocabularios indígenas $\mathrm{n}^{\circ} 33$, Tucson.

Bartolomé Miguel A. y M. Alicia Barabas

1982 Tierra de la palabra. Historia y etnografia de los chatinos de Oaxaca, INAH, México. 
1990 La presa Cerro de Oro y el ingeniero el Gran Dios, INI/CONACULTA, México.

BaSALENQue Diego

1975 Vocabulario de la lengua castellana vuelta a la matlatzinca, Leonardo Manrique (ed.), Biblioteca Enciclopédica del Estado de México, Toluca.

BASChET Jérome

2000 "Âme et corps dans l'Occident médiéval: une dualité dynamique entre pluralité et dualisme », Archives de sciences sociales des religions, 112, pp. 5-29.

Basseta Domingo de

2005 Vocabulario de la lengua quiché, René Acuña (ed.), IIF/CEM/UNAM, México.

BEATY DE FARRIS Kathryn

2002 Diccionario básico del mixteco de Yosondua, Oaxaca, Instituto lingüístico de Verano, Vocabularios indígenas $n^{\circ} 46$, México.

BENNETT Wendell y Robert ZiNGG

1935 The Tarahumara indian tribe of Northern Mexico, The University of Chicago Press, Chicago, Illinois.

BiRd GrinNell George

1972 The Cheyenne Indians: war; ceremonies and religion, University of Nebraska Press, Lincoln/Londres.

Bozzolı E. María

1979 El nacimiento y la muerte entre los bribris, Universidad de Costa Rica, San José.

BRANIFF Beatriz

1995 «Diseños tradicionales mesoamericanos y norteños. Ensayo e interpretación ", in María de los Dolores Soto de Arechavaleta y Barbro Dahlgren (eds), Arqueología del norte y del occidente de México. Homenaje al Doctor J. Charles Kelley, IIA/UNAM, México, pp. 181-210.

Brown Michael

1981 Magic and meaning in the world of Aguaruna Jivaro of Peru, tesis de doctorado en antropología, University of Michigan, Michigan.

BUTLER Inez

1997 Diccionario zapoteco de Yatzachi el Bajo, Yatzachi el Alto, Instituto lingüístico de Verano, Vocabularios indigenas $\mathrm{n}^{\circ} 37$, Tucson.

Carrasco Pedro

1960 Pagan rituals and beliefs among the Chontal indians of Oaxaca, Mexico, UCP, Anthropological records, Berkeley/Los Angeles.

\section{CARSON Ruth y Francis EACHUS}

1978 "El mundo espiritual de los kekchies », Guatemala indigena, XIII (1-2), pp. 38-73, Instituto indigenista nacional, Guatemala. 
Casillas Romo Armando

1990 Nostalgia mítica de un pueblo. Medicina tradicional huichola, Universidad de Guadalajara, Guadalajara.

Chamoux Marie Noëlle

1989 «La notion nahua d'individu: un aspect du tonalli dans la région de Huauchinango, Puebla », in Dominique Michelet (ed.), Enquêtes sur l'Amérique moyenne. Mélanges offerts à Guy Stresser-Péan, INAH/ CONACULTA/CEMCA, México, pp. 303-310.

\section{Chapman Anne}

1985 Los hijos del copal y la candela. Ritos agrarios y tradición oral de los lencas de Honduras, 3 vols, IIA/UNAM, México.

\section{CHEMIN BÄSSLER Heidi}

1984 Los pames septentrionales de San Luis Potosi, INI, México.

\section{Ciudad Real Antonio}

1995 Calepino de Motul: diccionario maya-español, Ramón Arzápalo Marín (éd.), 3 vols, IIA/UNAM, México.

Clark Lawrence

1981 Diccionario popoluca de Olutla, Instituto lingüístico de Verano, México.

Clark Lorenzo y Nancy Davis de Clark

1974 Vocabulario popoluca de Sayula, Instituto lingüístico de Verano, Vocabularios indígenas $n^{\circ} 4$, México.

Cline Howard

1944 "Lore and deities of the Lacandon Indians. Chiapas, Mexico », Journal of Códice Florentino American Folklore, LVII (223-226), pp. 107-115, Philadelphia.

1950-1963 ver Sahagún

Córdoba Juan de

1987 Vocabulario en lengua çapoteca, SEP/INAH, México.

Córdova Olivares Francisco R.

1990 "Apuntes sobre la cosmovisión de los totonacas de la región de Huehuetla, Pue ", Tlacatl, 22, Xalapa.

\section{Delgado Thays Carmen}

1965 Religión y magia en Tupe (yauyos), Instituto de Estudios Etnológicos del Museo Nacional de la Cultura Peruana/Departamento de Antropología de la Universidad Nacional Mayor de San Marcos, Lima.

Dávila Cabrera Patricio

2000 "La frontera noreste de Mesoamérica: un puente cultural », in Marie-Areti Hers (ed.), Nómadas y sedentarios en el Norte de México. Homenaje a Beatriz Braniff, IIE/IIH/IIA/UNAM, México, pp. 79-90.

Diccionario maya Cordemex

1980 Alfredo Barrera Vázquez (ed.), Ed. Cordemex, Mérida. 
Dow James

1975 The Otomi of the Northern Sierra de Puebla, Mexico. An ethnographic outline, LatinAmerican studies center, Monograph series $n^{\circ} 12$, Michigan

DUQUESNOY Michel State University, East Lansing, Michigan.

2001 Le chamanisme contemporain Nahua de San Miguel Tzinacapan, Sierra Norte de Puebla, Mexique, tesis de doctorado, Université de Lille 3, Lille.

Durán Diego de

1967-1984 Historia de las indias de la Nueva España e islas de la tierra firme, Ángel Ma Garibay K. (ed.), vol. I y II, Ed. Porrúa, México.

Dyk Anne y Betty StoudT

1973 Vocabulario mixteco de San Miguel el Grande, Instituto lingüístico de Verano, Vocabularios indígenas $n^{\circ} 12$, México.

ELMENDORF W. William

1967 "Soul loss illness in western North America », in Sol Tax (ed.), Indian tribes of aboriginal America. Selected papers of the XXIXth International Congress of Americanists, Cooper Square Publishers, Nueva York, pp. 104114.

Elson F. Benjamín y Donaciano GutiérReZ

1999 Diccionario popoluca de la Sierra de Veracruz, Instituto lingüístico de Verano, Vocabularios indígenas $\mathrm{n}^{\circ} 41$, México.

\section{Escalante Hernández Roberto}

1997 Diccionario matlatzinca-español, Colegio de lenguas y literatura indígenas, Instituto Mexiquense de Cultura, Toluca.

FAGETTI Antonella

1996 Cuerpo humano y naturaleza en la cosmovisión de un pueblo campesino, tesis de maestría en antropología social, ENAH/INAH/SEP, México.

FERNÁNIDEZ de OVIEDO Y VALdÉs Gonzalo

1840 Histoire de Nicaragua, Voyages, relations et mémoires de l'Amérique, Arthus-Bertrand Libraire-Éditeur, Paris.

FERRERO Luis

2000 Costa Rica precolombina: arqueología, etnología, tecnología, arte, Ed. Costa Rica, San José.

\section{Figuerola Pujol Helios}

2000 "El cuerpo y sus entes en Cancuc, Chiapas », Trace, 38, número especial El cuerpo, sus males y sus ritos, CEMCA, México, pp. 13-24.

2005 Les dieux, les hommes et les paroles, tesis de doctorado, université de Paris X, Nanterre.

Flanet Véronique

1977 Viviré si Dios quiere. Un estudio de la violencia en la Mixteca de la costa, INI, México.

1982 La maîtresse mort, Territoires, Berger-Lerault, Paris. 


\section{Furst Peter}

1972 "El concepto huichol del alma », in Peter Furst y Salomón Nahmad (eds), Mitos y arte huicholes, SEP, SepSetentas, México, pp. 7-113.

FonTANA Barnard L.

1989 Of earth and little rain. The Papago indians, University of Arizona Press, Tucson.

\section{GaLinier Jacques}

1979 N'yũhũ, les Indiens Otomis. Hiérarchie sociale et tradition dans le Sud de la Huasteca, Mission archéologique et ethnologique française au Mexique, Études mésoaméricaines série 2, México.

1990 La mitad del mundo. Cuerpo y cosmos en los rituales otomíes, UNAM/CEMCA/INI, México.

\section{Gallardo Ruiz Juan}

2005 Medicina tradicional p'urhépecha, El Colegio de Michoacán, Universidad Indígena Intercultural de Michoacán, Zamora.

García Alcaraz Agustín

1973 Tinujei. Los triques de Copala, Comisión del Río Balsas-Secretaría de Recursos Hidráulicos, México.

\section{García de León Antonio}

1969 "El universo de lo sobrenatural entre los nahuas de Pajapan, Veracruz », Estudios de Cultura Náhuatl, VIII, pp. 279-312, IIH/UNAM, México.

García Ruiz Jesús

1987 "Elementos para el análisis de la noción de persona entre los mocho: los componentes del Yo ", in Barbro Dahlgren (ed.), Historia de la religión en Mesoamérica y áreas afines, I Coloquio, IIA/UNAM, México, pp. 263-283.

García Souza Paola Paloma y Andrés Oseguera Montiel.

2001 Tiempos ceremoniales: ensayos de cosmogonia y dancística huave de San Mateo del Mar; Oaxaca, tesis de licenciado en etnología, ENAH/INAH/SEP, México.

GARNUNG Monique

2000 "Le corps et ses connivences chez les Amuzgo de Oaxaca à San Pedro Amuzgos », Trace, 38, número especial El cuerpo, sus males y sus ritos, CEMCA, México, p. 30.

GiLBERTI Maturino

1989-1997 Vocabulario en lengua de Mechuacan, Benedict Warren (ed.), Fimax Publicistas Editores, Morelia.

Goloubinoff Marina

1994 Relations sociales et commerce chez les Indiens nahuas du Balsas, 2 vols, tesis de doctorado, université de Paris X, Nanterre.

Goov Claude

1979 Diccionario triqui de Chicahuaxtla, Instituto lingüístico de Verano, Vocabularios indígenas $\mathrm{n}^{\circ} 20$. México. 
Goodwin Grenville

1938 "White Mountain Apache religion », American Anthropologist, 40 (1), pp. 24-37.

Gossen H. Gary

1975 "Animal souls and human destiny in Chamula », Man, 10 (1), pp. 448-461.

Güemez PIneda Miguel

2000 " La concepción del cuerpo humano, la maternidad y el dolor entre mujeres mayas yukatekas ", Mesoamérica, XXXIX, pp. 305-332.

Greenway S. Christine

1987 Summoning the soul: self and cosmos in quechua healing rites, tesis doctoral, University of Washington, Washington.

Guiteras Holmes Calixta

1961-1965 Perils of the soul. The world view of a tzotzil Indian, The Free Press of Glencoe, inc., Crowell-Collier Publishing Company, New York.

GutiÉrREZ EsPInosa Gabriela

1998 Cosmovisión femenina en una comunidad de la Sierra Norte de Puebla, tesis de licenciatura en antropología social, ENAH/INAH/SEP, México.

GuZmán Pantaleón de

1989 Compendio de nombres en lengua cakchiquel, René Acuña (ed.), IIF/UNAM, México.

Harrison Roy, Margaret Harrison y Cástulo García

1981 Diccionario zoque de Copainalá, Instituto lingüístico de Verano, Vocabularios indígenas $\mathrm{n}^{\circ} 23$, Tucson.

Hernández Cruz Luis, Victoria Torquemada Moisés y Donaldo Sinclair Craivford 2004 Diccionario hñähñu (otomi) del Valle del Mezquital, Estado de Hidalgo, Instituto lingüístico de Verano, México.

Hers Marie-Areti

1989 Los Toltecas en tierras chichimecas, IIE/UNAM, México.

Hoogshagen Nourdsy y Hilda Halloren de Hoogshagen

1993 Diccionario mixe de Coatlan, Instituto lingüístico de Verano, Vocabularios indígenas $\mathrm{n}^{\circ} 32$, México.

Hooper Wale

1920 The Cahuilla Indians, University of California Press, Los Ángeles-Berkeley.

HultKrantz Ake

1953 Conceptions of the soul among NorthAmerican Indians, Statens Etnografiska Museum, Estockholmo.

ICHON Alain

1973 La religión de los totonacas de la Sierra, INI, México.

InChaustegui Carlos

2000 "Entorno enemigo. Los mazatecos y sus sobrenaturales 》, Desacatos, invierno, México. 
Instituto lingüístico de Verano

1973 Diccionario totonaco de Papantla, Instituto lingüístico de Verano, Vocabularios indígenas $\mathrm{n}^{\circ} 16$, México.

JÄKLEIN Klaus

1974 Un pueblo popoloca, INI/SEP, México.

JAMIESON CAPEN Carole

1996 Diccionario mazateco de Chiquihuitlan, Instituto lingüístico de Verano, Vocabularios indígenas $n^{\circ} 36$, Tucson.

Keller C. Kathryn y Plácido Luciano

1997 Diccionario chontal de Tabasco, Instituto lingüístico de Verano, México.

Kelly Isabel

1956 Santiago Tuxtla, Veracruz. Cultura y salud, Secretaría de Salubridad y Asistencia, México.

KIRCHHOFF Paul

1943 "Mesoamérica: sus límites geográficos, composición étnica y caracteres culturales », Acta Americana, I (1), pp. 92-107, Los Ángeles/México.

KöHLER Ulrich

1995 Chonbilal ch'ulelal. Alma vendida. Elementos fundamentales de la cosmología y religión mesoamericanas en una oración maya-tzotzil, IIA/UNAM, México.

LA FARGE Olivier

1947 Santa Eulalia. The religion of a Cuchumatan indian town, The University of Chicago Press, Chicago, Illinois.

LA FARGE Olivier y Douglas Byers

1931 The year bearer's people, Department of Middle American Research, Tulane/University of Luisiana, Nueva Orleans.

LAUGHLIN Robert y Carol KarasiK

1988 The People of the bat: Mayan tales and dreams from Zinacantan, SIW Press, Washington/Londres.

Lewis Oscar

1963 Life in a mexican village. Tepoztlan restudied, University of Illinois Press, Urbana.

Lipp Frank J.

1991 The Mixe of Oaxaca. Religion, ritual and healing, University of Texas Press, Austin.

LisBona Guillén Miguel

1998 «Religión entre los zoques: una revisión de los estudios y perspectivas antropológicas », Inventario antropológico, IV, pp. 13-36, México.

LONG Rebecca y Sofronio CRUZ

1999 Diccionario zapoteco de Zoogocho, Instituto lingüístico de Verano, Vocabularios indígenas $\mathrm{n}^{\circ} 38$, México. 


\section{López Austin Alfredo}

1996 Cuerpo humano e ideología. Las concepciones de los antiguos nahuas, IIA/UNAM, México.

2001 "El núcleo duro de la cosmovisión y la tradición mesoamericana », in Johanna Broda y Félix Báez Jorge (eds), Cosmovisión, ritual e identidad de los pueblos indigenas de México, Biblioteca Mexicana, Fondo de Cultura Económica, México, pp. 47-65.

LÓPEz YePEs Joaquín

1826 Catecismo y declaración de la doctrina cristiana en lengua otomi, con vocabulario del mismo idioma [imprenta Alejandro Valdès], México.

LuPo Alessandro

2001 "La cosmovisión de los nahuas de la Sierra de Puebla », in Johanna Broda y Félix Báez Jorge (eds), Cosmovisión, ritual e identidad de los pueblos indigenas de México, Biblioteca Mexicana, Fondo de Cultura Económica, México, pp. 335-389.

MADSEN William

1960 The virgins children. Life in an Aztec village today, Greenwood Press Publishers, Westport, Connecticut.

MAK Cornelia

1959 "Mixtec medical beliefs and practices », América indigena, XIX (2) III, pp. 125-150, México.

MaRShall Mary Linn

1986 Illness in a Guatemala community, tesis de doctorado, Universidad de Yale, Bell and Howard Information Company, Ann Arbor.

Martínez GonzÁlez Roberto

2007 "El tonalli y el calor vital entre los nahuas: algunas precisiones », Anales de Antropología, 40 (II) [en prensa].

McKeEver Furst Jill Leslie

1995 The natural history of the soul in ancient Mexico, Yale University Press, New Haven/Londres.

McLean Duncan Earl

1984 "Night time and dream space for a Quiché Maya family ", XVII Mesa Redonda de la Sociedad Mexicana de Antropología, Ed. Bartolomé de las Casas, San Cristóbal de las Casas, pp. 397-400.

MENDELson Michael

1965 Los escándalos de Maximón. Un estudio sobre la religión y la visión del mundo de Santiago Atitlán, Tipografía Nacional, Guatemala.

Merrifield William R. y Alfred E. ANDERSON

1999 Diccionario chinanteco de la diáspora del pueblo antiguo de San Pedro Tlatepuzco, Oaxaca, Instituto lingüístico de Verano, Vocabularios indígenas $n^{\circ} 39$, México.

MerriL L. William

1992

Almas rarámuris, traducido por Lourdes Alvardi, Guillermo Palma y Cecilia Troop, INI/CONACULTA, México. 
Molina Alonso de

2000 Vocabulario en lengua castellana y mexicana, mexicana y castellana, Miguel León-Portilla (ed.), Porrúa, México.

MONAGHAN John

1995 The covenants with earth and rain. Exchange, sacrifice and revelation in Mixe society, University of Oklahoma Press, Norman/Londres.

Montoya Briones José de Jesús

1964 Atla, etnografia de un pueblo náhuatl, INAH, México.

Morán Pedro y Dionisio ZúÑIGA

1991 Arte breve y vocabularios de la lengua pocom, René Acuña (ed.), IIF/UNAM, México.

PAge Pliego Jaime Tomás

2002 Curandería tzotzil y procesos de formación, iniciación y de trabajo de sus practicantes, tesis doctoral, facultad de Filosofia y Letras, UNAM, México.

Pensinger Brenda J.

1974 Diccionario mixteco del este de Jamiltepec, Pueblo de Chajuco, Instituto linguístico de Verano, Vocabularios indígenas $n^{\circ} 18$, México.

Pitarch Pedro Ramón

1996 Ch'ulel: una etnografia de las almas tzeltales, Fondo de Cultura Económica, México.

2000 "Almas y cuerpo en una tradición tzeltal », Archives de sciences sociales des religions, 112, pp. 31-48.

PITT-Rivers Julian

1971 «Thomas Gage parmi les naguales: conceptions européenne et maya de la sorcellerie », L'Homme, II, pp. 5-31.

PonCe de León Pedro

1965 "Tratado de los dioses y ritos de la gentilidad », in Ángel María Garibay (ed.), Teogonía e Historia de los Mexicanos. Tres opúsculos del siglo XVI, Porrúa, Sepan cuantos, México, pp. 121-140.

Portal Arioso María Ana

1986 Cuentos y mitos de la zona mazateca, INAH, México.

Pride Leslie y Kitty Pride

1970 Vocabulario chatino de Tataltepec, Instituto lingüístico de Verano, Vocabularios indígenas $\mathrm{n}^{\circ} 15$, México.

2004 Diccionario chatino de la zona alta, Panixtlahuaca, Oaxaca, Instituto lingüístico de Verano, Vocabularios indigenas $n^{\circ} 47$, México.

REDFIELD Robert

1930 Tepoztlan, a mexican village. A study of folk life, The University of Chicago Press, Chicago/Londres.

REICHARD Gladys

$1970 \quad$ Navaho religion. A study of symbolism, Princeton University Press, Bolling series XVIII, New York. 
ReID Aileen A. y Ruth G. Bishop

1974 Diccionario totonaco de Xicotepec de Juárez, Puebla, Instituto lingüístico de Verano/SEP, México.

Reynoso Diego de

1916 Vocabulario de lengua mame, Sociedad Mexicana de Geografía y Estadística, México.

Reynoso Gonzélez Elpidia

1998 Vocabulario español-tlahuica, Colegio de lenguas y literatura indígenas/Instituto Mexiquense de Cultura, Toluca.

\section{RıviÈRE Claude}

1987 "Soul », in Mircea Eliade (ed.), The encyclopedia of religión, MacMillan Publishing Company, New York/Londres.

Rodríguez González Hugo

2002 El chamán y la cosmovisión entre los nahuas de la Sierra Norte de Puebla, tesis de licenciatura, antropologia social, ENAH/INAH/SEP, México.

Rodríguez López María Teresa

2000 Ritual, identidad y procesos étnicos entre los nahuas de la sierra de Zongolica, Veracruz, tesis de doctorado, antropología, UAM Iztapalapa, México.

Romero López Laura Elena

2003 Cosmovisión, cuerpo y enfermedad: el espanto entre los nahuas de Tlacotepec de Díaz, Puebla, tesis de licenciatura, etnohistoria, ENAH/INAH/SEP, México.

RoMNEY Kimball y Romaine RomNeY

1973 The Mixtecans of Juxtlahuaca, México, Robert E. Kreiger Publishing Co, Nueva York.

Rupp Jaime y Nadine Rupp

1996 Diccionario chinanteco de San Juan Lealo, Oaxaca, Instituto lingüístico de Verano, Vocabularios indígenas $n^{\circ} 35$, México.

Ruz Mario Humberto

1983 "Aproximación a la cosmología tojolabal », in Lorenzo Ochoa y Thomas A. Lee Jr. (eds), Antropología e historia de los mixe-zoques y mayas (Homenaje a Frans Blom), UNAM/Brigham Young University, México.

SAHAGÚN Bernardino de

1950-1963 Florentine Codex. General History of the Things of New Spain, traducido por Arthur J. O. Anderson y Charles E. Dibble, University of New Mexico Press, Monographs of the School of American Research, Santa Fe, New Mexico.

SÁnchez y Díaz de Rivera María Eugenia

1978 Temps, espace et changement social. Perspectives à partir de la communauté indigène de San Miguel Tzinacapan, tesis doctoral, EHESS, Paris.

SANDSTROM Alan R.

1991 Corn is our Blood. Culture and ethnic identity in a contemporary Aztec village, University of Oklahoma Press, Norman/Londres. 


\section{Schoemals Alvin y Louise Schoehals}

1965 Vocabulario mixe de Totontepec, Instituto lingüístico de Verano, Vocabularios indígenas $\mathrm{n}^{\circ} 14$, México.

\section{Schultze Jena Leonhard}

1947 La vida y las creencias de los indigenas quichés de Guatemala, traducido por Antonio Goubaud Carrera, Ministerio de Educación, Biblioteca de Cultura Popular, Guatemala.

SignORINI Italo y Alessandro LuPo

1989 Los tres ejes de la vida. Almas, cuerpo, enfermedad entre los nahuas de la Sierra de Puebla, Universidad Veracruzana, Xalapa.

Silva José de la Luz

1972 "Notas sobre religiosidad totonaca », Estudios Indigenas, II (1), pp. 87-97, México.

SKINNER Leonard E. y Marlene B. SKINNER

2000 Diccionario chinanteco de San Felipe Usila, Oaxaca, Instituto lingüístico de Verano, Vocabularios indígenas $n^{\circ} 43$, México.

Stairs Kreyer Glenn Albert y Emily Florence SchaFe de Stairs

1981 Diccionario huave de San Mateo del Mar, Instituto lingüístico de Verano, Vocabularios indígenas, México.

StONE Doris

1949 The Boruca of Costa Rica, Peabody museum of American archaeology and ethnology, XXVI (2), Harvard University, Cambridge, Massachusetts.

Stubiblefield Morris y Carol Miller de Stubblefield

1991 Diccionario zapoteco de Mitla, Instituto lingüístico de Verano, Vocabularios indígenas $n^{\circ} 31$, México.

Tapia Zenteno Carlos de

1985 Paradigma apologético y' noticia de la lengua huasteca, René Acuña (ed.), IIF/UNAM, México.

TEDLock Barbara

1982 Time and the highland Maya, University of New Mexico Press, Albuquerque.

THOMPSON J. Eric S.

1927-1932 "Ethnology of the Mayas of southern and central British Honduras ", Field museum of Natural History Anthropological Series, XVII (1-4), pp. 27-213, Chicago.

\section{TSCHAUPIK Harry}

1968 Magia en Chucuito, Instituto Indigenista Interamericano, México.

Urbano Alonso

$1990 \quad$ Arte breve de la lengua otomi y vocabulario trilingüe español-náhuatl-otomí, René Acuña (ed.), IIF/UNAM. México.

Vallejo Reyna Alberto

2001 Por los caminos de los antiguos nawales: Ri Laj Mam y el nawalismo maya tzutuhil en Santiago Atitlán, Guatemala, Fundación CEDIM, Iximulew, Guatemala. 
VeCSEY Christopher

1983 Traditional Ojibwa religion and its historical changes, The American Philosophical Society, Philadelphia.

Velásquez Gallardo Pablo

1978 Diccionario de lengua phorhepecha, Fondo de Cultura Económica, México.

Villa Rojas Alfonso

1987 Los elegidos de Dios. Etnografia de los mayas de Quintana Roo, INI, México.

1990 Etnografia tzeltal de Chiapas: Modalidades de una cosmovisión prehispánica, Gobierno del Estado de Chiapas/Consejo Estatal para el Fomento de la

Vogt Evon Z. Investigación y la Difusión de la Cultura, México.

1969 Zinacantan. A Maya community in the highlands of Chiapas, Harvard University Press, Cambridge, Massachussetts.

Weigand Phil y Alecia García

1992 "Muerte y luto entre los huicholes del Occidende de México ", in Phil Weigand (ed.), Ensayos sobre el Gran Nayar entre coras, huicholes y tepehuanes, INI/CEMCA/Colegio de Michoacán, México, pp. 215-233.

Weiss Gerald

1975 Campa cosmology. The world of a forest tribe in South America, Florida Atlantic University, Anthropological Papers of the Museum of Natural History 52 (5), Nueva York.

Weisz Carrington Gabriel

1996 "Personificaciones somáticas », Poligrafias. Revista de literatura comparada, 1, pp. 65-82, México.

WHEELER Romayne

1998 La vida ante los ojos de un rarámuri, Ed. Agata, Guadalajara.

Weitlaner Roberto y Carlo Antonio Castro

1973 Papeles de la Chinantla VII: Usila (Morada de Colibríes), Museo Nacional de Antropología, México.

WhITTAKer Arabelle y Viola WARKentin

1965 Chol text on the supernatural, Instituto lingüistico de Verano/University of Oklahoma, Norman.

WiLlians García Roberto

1963 Los tepehuas, Universidad Veracruzana, Xalapa.

WisDom Charles

1961 Los chortis de Guatemala, Seminario de integración social guatemalteca, Guatemala.

WONDERLY L. William

1946 "Textos en zoque sobre el concepto de nagual », Tlalocam. A journal of source materials on the native cultures of Mexico, II, pp. 97-105, La Casa de Tlaloc, México.

ZINGG Robert M.

$1982 \quad$ Los huicholes. Una tribu de artistas, 2 vols, INI, México. 